\title{
Orígenes del fair use
}

\author{
Fair use's origins
}

\author{
CAROLINA IBÁÑEZ KOLLMANN \\ Abogada
}

RESUMEN El modelo norteamericano del fair use, con su configuración flexible y como válvula de equilibrio normativo para el copyright, ha demostrado estar a la altura de los desafíos que supone el avance tecnológico, permitiendo que el sistema normativo del copyright tenga mayor capacidad de adaptación y, con ello, que el flujo económico y cultural asociado a estos nuevos contextos tecnológicos se transforme en un beneficio para la sociedad. En este escenario, el derecho de autor ha reforzado progresivamente sus alcances, sancionando cada vez con mayor dureza las infracciones a su normativa, lo que ha ocasionado profundas fricciones entre el avance de los cambios tecnológicos y los regímenes normativos que los regulan. La consecuencia más directa de esta expansión del copyright ha sido la sostenida disminución de los alcances de las excepciones y limitaciones al derecho de autor, provocando un importante desequilibrio en su regulación, lo que se traduce en respuestas ineficientes u obstructivas para el interés público y privado. La historia del copyright norteamericano, y en particular la gestación del fair use desde sus raíces en la jurisprudencia y doctrina británica premoderna hasta nuestros días, ofrece interesantes elementos de análisis para una cabal comprensión de la actual crisis del copyright y aporta también antecedentes que apuntan a la conveniencia de la incorporación de un mecanismo garantista como el fair use en nuestro país, para enfrentar este contexto de expansivo control autoral. 
PALABRAS CLAVE Fair use, fair abridgment, derecho de autor, excepciones y limitaciones, originalidad.

ABSTRACT The American model of fair use, with its flexible configuration and as an equalizing valve of rules for the copyright, has proved to be up to the challenges involved in technological advance, allowing the copyright regulatory system to have a greater adaptability and thus that economic and cultural flows associated with these new technological contexts are transformed into a benefit for society. In this scenario, the copyright has progressively strengthened its scope, by punishing increasingly with more harshness the infringement to its regulation, which has caused deep friction between the advance of technology changes and regulatory regimes that govern them. The most direct consequence of this inflation of copyright has been sustained decrease in the scope of exceptions and limitations to copyright, causing a significant imbalance in their regulation, which results in inefficient or obstructive answers for the public and private interest. The history of American copyright and in particular, the gestation of fair use, beginning with its roots in the premodern British jurisprudence and doctrine, provides interesting elements of analysis for an understanding of the current crisis of copyright and also provides a background that point to the desirability of incorporating a guarantor as fair use mechanism in our country, to face this expansive context of authorial control.

KEYWORDS Fair use, fair abridgment, copyright, exceptions and limitations, originality.

\section{INTRODUCCIÓN}

Los orígenes del fair use se remontan a las primeras décadas del siglo XVIII, en plena génesis de la primera legislación del copyright: el Estatuto de Ana de Inglaterra, promulgado en I7ı Y. Ya entonces la ampliación de los alcances del copyright era uno de los principales motores de su desarrollo y el fair use fue el vehículo más eficaz para su consecución. En perspectiva histórica, la noción del fair use como una excepción ocasional y limitada del copyright es refutable; abundan sen- 
tencias y doctrina que lo reconocen como su contraparte equivalente desde sus orígenes. ${ }^{1}$

Por esos años se desarrollaron los principales criterios de análisis casuístico que posteriormente conformarían el fair use del modelo norteamericano moderno, lo que da cuenta del avanzado desarrollo alcanzado por las cortes británicas en este período. Efecto en el mercado, cantidad copiada y usos transformativos, entre otros criterios, dan cuenta de la continuidad evolutiva entre el copyright británico y el actual copyright norteamericano.

La prehistoria del fair use está marcada por una serie de casos de fair abridgment (resúmenes justos) litigados en las cortes de Inglaterra entre I7IO y I 84I. De un examen general de estos casos puede concluirse que:

- El estatuto del copyright desde sus inicios fue más allá de los simples actos de reproducción mecánica de obras protegidas. A mediados del siglo XVIII, las cortes ya habían desarrollado avanzados criterios de análisis para establecer la legalidad o ilegalidad de los resúmenes o compendios de obras protegidas, como la distinción entre resúmenes justos o de buena fe y los injustos o de mala fe, distinción que de por sí expande los alcances del copyright de entonces.

- Existe una continuidad sustancial entre el fair abridgment de la era premoderna de Inglaterra y el actual fair use de Estados Unidos (Sag, 2OII).

Fue la jurisprudencia británica de la era premoderna la responsable de los primeros avances doctrinarios del copyright, bajo un análisis casuístico que ampliaría los márgenes de protección del copyright y profundizaría los criterios de justicia y buena fe para el examen de legalidad de los usos derivados de obras originales. ${ }^{2}$

En este artículo revisaremos los principales desarrollos doctrinarios y jurisprudenciales de este período, para luego detenernos en el impacto

I. En este sentido, Samuelson (2009) se refiere al fair use como una parte integral y esencial del copyright norteamericano.

2. La expresión «usos derivados de obras originales» se refiere a los usos característicos de este período, que comprende resúmenes, extractos, traducciones y compilaciones. 
que estos procesos ejercieron en el desarrollo del copyright norteamericano, y, en particular, en el diseño del fair use del caso Folsom v. Marsh y sus repercusiones en su actual normativa.

\section{LA ERA PREMODERNA DEL COPYRIGHT EN INGLATERRA}

El copyright de la primera fase premoderna fue entendido como un derecho de estrechos alcances, basado en una noción estrictamente mecánica, que atendería a controlar exclusivamente las reproducciones íntegras de obras originales, a favor de acotados monopolios de editoriales e imprentas.

Sus primeras regulaciones fueron concebidas como privilegios especiales para grupos de editores y de imprentas, potestad que les otorgaba un control monopólico de las reproducciones de obras originales, con atribuciones para tomar medidas contra quienes reproducían obras fuera del privilegio. Los de mayor importancia:

I. Royal privilege (privilegio real): el de mayor prestigio, concedido por la Corona, a peticiones de patentes de letras, o como licencias para editores e impresores y, lo menos frecuente, para autores.

2. Parliamentary privilege (privilegio parlamentario): cada cámara del parlamento (comunes y lores) reclamaban tener en sus atribuciones el derecho a controlar la publicación de sus votos, discursos, debates y actuaciones. Ninguna persona tenía permitido publicar sin el expreso consentimiento de los parlamentarios. Estas autorizaciones con el tiempo fueron forjando un importante grupo editorial que monopolizó las publicaciones de interés público.

3. Stationer's copyright: también un privilegio concedido por la Corona, pero con su origen en una carta real concedida en I 557 a la Compañía de Papelerías, gremio integrado por imprentas, libreros y otros agentes de la industria del libro. Éste sería eventualmente uno de los grupos que más presionaría por la legislación del copyright, frente a la pujante importación de libros que se vivió en los primeros años del siglo XVIII (Gómez-Aróstegui, 20I0: I25I-6). 
Las importaciones de libros desde Escocia, tras su unión a Inglaterra el año I707, las disputas judiciales por la impresión de obras fuera de los grupos reconocidos por privilegio y la creciente demanda de estas impresiones independientes, fueron debilitando el hasta entonces blindado mercado de los privilegios editoriales, desatando fuertes presiones para la elaboración de un estatuto amplio de protección, que fuera capaz de garantizar la completa protección de las reproducciones nacionales (Gómez-Aróstegui, 2010: I 256).

El intenso proceso de lobby tuvo su desenlace al poco tiempo, con la publicación del Estatuto de Ana el ro de abril de i7ıo, legislación que limitaría los alcances de protección del copyright a la reproducción íntegra de obras protegidas, rediseñando de esta forma el mercado de las editoriales desde un concepto derechamente comercial de la propiedad autoral.

Señala el Estatuto de Ana en su encabezado: «Una ley para estimular el aprendizaje, por la adquisición de derechos de copias de libros impresos a los autores o compradores de dichas copias, durante los tiempos en ésta mencionado».

El mandato de la ley señala:

El autor de cualquier libro o libros ya impresos, que no haya transferido a otra persona la o las copias de tal libro o libros, acción o acciones del mismo, o librero o libreros, o el impresor o impresores, u otra persona o personas, que tenga o haya comprado o adquirido la copia o copias de cualquier libro o libros con el fin de imprimir o reimprimirlos, tendrá el derecho y libertad exclusivos para imprimir dicho libro y libros por el plazo de 2 I años, a partir del mencionado día ıo de abril de I7IO y no más; y que el autor de cualquier libro ya compuesto y no impreso y publicado, o que en adelante será compuesto, y su cesionario o cesionarios, tendrá la exclusiva libertad de imprimir y reimprimir dicho libro o libros por el plazo de I4 años. ${ }^{3}$

La sanción al infractor pretendía ser ejemplar. Señalaba la ley que quien imprimiera, reimprimiera o publicara un libro sin el consentimiento de su autor o propietario, debía entregar todas las copias y las hojas

3. Statute of Anne, disponible en <http://www.copyrighthistory.com/anne.html>. Todas las traducciones son nuestras, salvo que se indique otra cosa. 
de todas y cada una de las copias al legítimo propietario y pagar un penique por cada hoja que se encontrara en su custodia.

Como puede observarse, el Estatuto de Ana atendía el conflicto más lesivo para los intereses de editores e impresores de aquel entonces, la reimpresión de obras completas. Esta respuesta legal, con serias sanciones para su infracción, atiende a un contexto de masiva reproducción no autorizada de obras completas, que amenazaba en sus bases a la pujante empresa editorial. Es la respuesta a un inesperado cambio de condiciones producto del avance tecnológico ${ }^{4}$ y la ampliación del mercado sobre obras protegidas, con las nuevas relaciones comerciales más allá de las fronteras nacionales.

Siendo el principal objetivo del nuevo estatuto proteger exclusivamente el monopolio de librerías y editoriales de Londres, los resúmenes (abridgments), traducciones, compilaciones u otros trabajos derivados, quedaron fuera de su regulación. ${ }^{5}$ Por esos primeros años del acta, los usos derivativos, en pleno auge, eran observados comúnmente como un beneficio para la comunidad y aún no representaban una lesión importante a los intereses de las principales empresas editoriales.

Sin embargo, la discusión en torno a la legalidad de estos usos al poco tiempo cobró fuerzas, pero los argumentos en su defensa prevalecieron. Una parte mayoritaria de la doctrina y jurisprudencia del período reconocía en los trabajos derivados de obras originales un valor independiente de su fuente, que reportaba un beneficio para la comunidad al facilitar el acceso al conocimiento. En uno de los más tempranos juicios sobre propiedad intelectual —Burnett v. Chetwood del año I72I-, la corte reconoce las traducciones como nuevos trabajos independientes de la obra original, señalando que éstas trascendían el mero arte mecánico de la reimpresión, involucrando las habilidades, estilo y expresión propios del traductor. ${ }^{6}$

4. Para un análisis a fondo de la influencia de los cambios tecnológicos en el derecho de propiedad intelectual, véase Sánchez (2004).

5. Para algunos, esta omisión estaría influenciada por una nueva práctica social entre autores, librerías y el público lector. Otros observan, desde una óptica estrictamente jurídica, que el Estatuto de Ana es una transición de regímenes, desde uno de licencias y regulación de marcas a otro de derechos de propiedad. Para conocer este debate, véase Patterson y Lindberg (I99I), Feather (I988) y Deazley (2004).

6. Burnett v. Chetwood, Burnet's Bill of Complaint and Chetwood's Answer, The Na- 
Esta forma de entender los alcances del copyright se repite en diversos escritos y sentencias de aquellos años; el límite para la infracción daba un amplio margen de libertad para las obras derivadas de originales. William Blackstone, en su libro Commentaries on the laws of England, describe el copyright en términos de identidad: «las mismas concepciones, vestidas en las mismas palabras, deben ser necesariamente la misma composición». Para el autor, la infracción del copyright requiere un nivel evidente de similitud en «identidad» (en Sag, 20I I: I4). Estas nociones dan cuenta de un contexto abiertamente tolerante a la apropiación parcial y a los resúmenes de obras originales protegidas.

Otro entendido generalizado del período consideraba que la libertad de los autores para resumir obras preexistentes respondía a que toda obra original una vez publicada pasaba a ser una parte integrante de la esfera del uso público. Estas prácticas cobraron importancia en el debate y eran defendidas por su consecuente beneficio para la diseminación del conocimiento científico, técnico y cultural. Como señalara Richard Godson en I 823: «Pareciera que los libros para ciertos propósitos, más allá del mero acto de su lectura, pueden ser usados por el público [...]. Pueden ser tomados como base de trabajo para otras labores literarias» (citado en Sag, 201 2: I3).

El autor, ensayista y comentarista Samuel Johnson, el más destacado defensor del derecho al abridgment, en su artículo "Considerations on the case of Dr. Trapp's sermons, abridged by Mr. Cave», ${ }^{7}$ plantea en I739 tres fundamentos principales para su defensa:

- Justicia: resumir un libro no es violación del derecho del propietario ya que es condición original de su propiedad la eventualidad de ser objeto de resumen.

- Los resúmenes que reducen obras de gran extensión son vitales para el desarrollo educacional: facilitan la transmisión del conocimiento.

tional Archives (I72I), Primary Sources on Copyright I 450-I900. Disponible en <http:// www.copyrighthistory.org/cgi-bin/kleioc/oo Io/exec/showTranscription/\%22uk_I 72 Ia_ im_OOI_OOOI.jpg\%22>.

7. Citado en Sag (20I I: I 5). Llama la atención que Johnson participara en la revista que más polémica ocasionó en torno al uso de resúmenes y extractos sin autorización de obras publicadas. 
- Las convenciones establecidas en la industria de la imprenta avalan la legalidad de esta práctica. El resumen es un acto en sí legal y justificable por una serie ininterrumpida de precedentes: todo tipo de resumen es publicado con la firma de su autor y el respaldo de una editorial, sin un rastro de clandestinidad (Sag, 20II: I 5 ).

En conclusión, para muchos los resúmenes eran considerados nuevas obras legítimas y legales, y dadas sus utilidades y méritos, merecedoras de incentivo.

Así es como numerosas fuentes, partiendo por el propio Estatuto de Ana, y siguiendo con las conclusiones de las primeras sentencias - como el caso Burnet v. Chetwood- y los escritos de Blackstone, Godson y Johnson, sugieren una noción restrictiva de los alcances del copyright bajo la primera legislación del Estatuto de Ana. Sin embargo, simultánea y continuamente, se desarrollaba una abundante base crítica a esta noción del copyright.

En este mismo período abundan fuentes que demuestran un álgido debate sobre la legalidad del abridgment. Incluso antes de ser publicado el Estatuto de Ana, en I704 el escritor Daniel Defoe señalaba: «el abridgment sin el consentimiento del autor equivale a una especie de robo que ahora está en plena práctica en Inglaterra». ${ }^{8}$

Hacia el año $\mathrm{I} 737$, el debate fue llevado adelante por editoriales y autores que nuevamente iniciaron un fuerte proceso de lobby en la Casa de los Comunes para la introducción de una nueva ley que cubriera las insuficiencias del Estatuto. El objetivo: establecer «la ilegalidad de la impresión, publicación, importación o venta de cualquier resumen o traducción de una obra protegida, sin el consentimiento del autor o propietario de los derechos de la obra, durante los tres primeros años desde la publicación de ésta». ${ }^{9}$ Este afán de monopolización de resúmenes y traducciones de obras originales da cuenta de lo ampliamente comunes que ya eran estas prácticas por aquellos años, resguardadas por el silencio de la ley y la costumbre.

8. Daniel Defoe, «An Essay on the Regulation of the Press» (I 704), disponible en <http:// www.copyrighthistory.org/cgi-bin/kleioc/ooro/exec/ausgabeCom/\%22uk_I704\%22>.

9. Esta ley fue denominada An Act for the Encouragement of Learning, introducida a la Casa de los Comunes el 3 de marzo de I737. Disponible en <http://www.copyrighthistory.org>. 
El debate cobró especial fuerza a raíz del pujante desarrollo de nuevos formatos de edición, en particular con las publicaciones de revistas mensuales. En este contexto, la revista Gentleman's Magazine, dirigida por Edward Cave, protagonizó duras polémicas a propósito de sus frecuentes publicaciones de extractos y resúmenes de libros protegidos por copyright.

En el año I739, Cave es demandado por la editorial Austen, Gilligan and Clark por publicar en su revista extractos de 37 páginas de las 69 del libro original del Dr. Trapp, The nature, folly, sin and danger of being righteous over-much. Los extractos reproducidos sumaban un total de I 3 páginas. La defensa argumentó que la revista era libre de publicar extractos cortos, fragmentos de libros, panfletos y otros escritos recientemente publicados, y que finalmente esta práctica beneficiaba a los propietarios de dichas obras. ${ }^{10}$ Pese a que la jurisprudencia de entonces mantenía su adhesión al argumento de Johnson (quien fundamentaba la legalidad del abridgment por una serie ininterrumpida de precedentes), Lord Hardwicke, quien tuvo una activa participación en los primeros casos de propiedad intelectual, sentenció a favor del demandante, indicando que una reproducción de I 3 páginas de extractos de una obra de 69 era excesiva. ${ }^{11}$ Sin embargo, esta decisión, una de las primeras sobre el abridgment, perdió notoriedad tras la resolución pro-abridgment que posteriormente el mismo Lord Hardwicke pronunciara en Gyles v. Wilcox, dos años más tarde.

En este caso, los demandantes acusaron a Wilcox de utilizar fragmentos textuales de la enciclopedia The history of the pleas of the crown, de Sir Matthew Hale, omitiendo algunos antecedentes, y agregando traducciones de algunas citas del texto, del latín y francés al inglés. La defensa de Wilcox señaló que este abridgment estaría fuera del alcance del Estatuto de Ana, y dado que el estatuto respondía a intereses monopólicos, sus alcances debían ser interpretados restrictivamente (Sag, 20 I I: 20). Hardwicke, rechazando este argumento, destacó que el principal objetivo del acta era el asegurar la protección de la propiedad de los libros para sus autores o titulares, en recompensa por su trabajo.

Io. Auster v. Cave. I739 (en Sag, 201 I: I8).

I I. Cuatro años más tarde, Cave obtuvo sentencia favorable tras ser demandado por otro caso de abridgment que apareció en su revista, en Cogan v. Cave, I743. 
Luego añade: «Cuando los libros son en apariencia resumidos, indudablemente están dentro del alcance del Estatuto de Ana, y son una mera evasión del estatuto, y no pueden ser llamados un resumen». Pero a continuación señala:

Esta posición no debe ser llevada hasta el punto de restringir a las personas de hacer un real y justo resumen, para resúmenes que con toda propiedad pueden ser reconocidos como un nuevo libro [...] porque en él está puesta la invención, aprendizaje y juicio del autor, y en muchos casos son extremadamente útiles, aunque en otros puedan ser perjudiciales, por equivocar o cercenar el sentido de un autor. ${ }^{12}$

Como puede observarse, Hardwicke por una parte plantea los alcances del copyright del Estatuto de Ana en un sentido más amplio al usualmente aplicado, extendiendo su aplicación a los resúmenes considerados «en apariencia resumidos» (unfair abridgments), y, por otra, otorga un abierto reconocimiento legal a los resúmenes considerados reales y justos, los fair abridgments.

Esta sentencia ha sido entendida como el origen del fair use de Inglaterra, decisión que ampliaría significativamente los alcances de protección del Estatuto de Ana. El mismo método emplearía cien años más tarde el juez norteamericano Joseph Story, en Folsom v. Marsh.

Tras la decisión de Gyles v. Wilcox, la discusión doctrinaria y jurisprudencial apuntó a delimitar las fronteras entre fair or bona fide abridgment y el injusto o de mala fe. Al respecto, señala Richard Godson en I823:

Un hombre puede con justicia adoptar una parte del trabajo de otro; él puede hacer uso del trabajo de otros para la promoción de la ciencia y el beneficio del público, pero hecho esto, la pregunta será ¿fue tomada la materia con justicia desde esa óptica y sin lo que podría llamarse un animus furandi [intención de robar]?

I2. Cita extraída de Sag (20I I: 20) (el énfasis es nuestro). El texto completo de Barnardiston, Report of Gyles v. Wilcox (Londres, I74I), está disponible en <http://www. copyrighthistory.org/cgi-bin/kleioc/ooro/exec/ausgabe/\%22uk_I74I\%22>. Otros comentarios de la sentencia en Commentary on: Gyles v. Wilcox (Atkyn's Reports), United Kingdom ( $174 \mathrm{I}$ ), disponible en <http://www.copyrighthistory.org/cgi-bin/kleioc/ooıo/ exec/ausgabeCom/\%22uk_I74I\%22>. 
Paulatinamente, se incorporaron nuevos elementos de examen, tales como la cantidad de material sustraído de la obra original y la importancia de los fragmentos extraídos, en atención a la intención o sentido original de la obra resumida. Sin embargo, los criterios base se ciñeron a lo resuelto por Hardwicke en Gyles v. Wilcox, distinguiendo el «resumen real y justo» del resumen «en apariencia resumido».

El desarrollo de estos criterios al poco tiempo amplió considerablemente los alcances originalmente restringidos del Estatuto de Ana. Se logró extender el ámbito de aplicación del copyright a todos los usos derivativos, asegurando a la vez la posibilidad de legalizar dichos usos mediante las defensas del fair abridgment.

Esta nutrida tradición del copyright de la era premoderna británica sentaría las bases para su regulación en el mundo moderno.

\section{CRITERIOS DE ANÁLISIS DEL FAIR USE EN LA ERA PREMODERNA}

El examen del abridgment de la era premoderna arroja una sorprendente continuidad con el fair use moderno. La indeterminación conceptual del modelo propició la discusión en torno a sus límites y el desarrollo de numerosos criterios de análisis para la determinación de legalidad por la vía casuística, que luego serían continuados por la doctrina norteamericana, cien años más tarde.

Los principales criterios de análisis forjados en este período fueron el análisis casuístico, la cantidad copiada, el efecto en el mercado, el efecto substitutivo y los usos transformativos (grado de labor y habilidad autoral).

\section{ANÁLISIS CASUÍSTICO}

Tal como ocurre en la actualidad con la aplicación del fair use, la determinación de legalidad del abridgment por la vía casuística fue objeto de diversas críticas, debido a la incertidumbre asociada al resultado de sus aplicaciones. Pero para entonces había consenso en que las características de cada caso hacían imposible la aplicación de normas generales y estáticas para su resolución. El análisis caso a caso era, y sigue siendo, una necesidad para la determinación de la legalidad o buena fe 
de un abridgment o fair use. ${ }^{13}$ Como Robert Maugham observaba en I 828: «Es difícil definir los límites exactos a los que un compilador está confinado en sus extractos o citas del autor original, o de resúmenes o compilaciones previas. En cada caso particular debe ser indagada y considerada la concurrencia de circunstancias peculiares» (citado en Sag, 2OII: 24).

Maugham no tardó en advertir que esta práctica podía originar contradicciones legales y doctrinarias, producto de la inconsistencia e incertidumbre del sistema, entendiendo que estos efectos no eran síntoma de una doctrina incipiente e inmadura. Había conocimiento de que la dinámica de los conflictos en torno a la justicia de los usos de obras originales resistía toda norma de aplicación general. ${ }^{14}$

La mayoría de los casos y publicaciones del período revisadas por Sag (20II) evidencian la importancia del análisis caso a caso para la determinación de legalidad o buena fe de cada abridgment.

CANTIDAD COPIADA (O IMPORTANCIA DE LA PARTE SUSTRAÍDA EN RELACIÓN A LA OBRA PROTEGIDA COMO UN TODO)

Este criterio está estrechamente vinculado al tercer factor de análisis del artículo 107 (3) del Copyright Act de 1976 de Estados Unidos, ${ }^{15}$ y tuvo un rol central en la discusión jurisprudencial del período premoderno. Numerosos casos fueron y siguen siendo debatidos en torno a este criterio.

En Dodsley v. Kinnersley (Sag, 20II: 25), caso relacionado a los resúmenes en revistas, la editorial de Dodsley contrató a Samuel Johnson para la primera edición de dos volúmenes del texto Rasselas, The

I3. En este sentido, Samuelson argumenta que la actual legislación del fair use «es probablemente más coherente y más predecible de lo que muchos comentaristas han percibido, una vez que se reconoce que los casos de fair use tienden a caer en patrones comunes» (2009: 254I).

I4. El autor cita el caso Dodsley v. Kinnersley de I76I, donde Sir Thomas Clarke señala: «la materia objeto de esta demanda ha sido tan a menudo vista ante el tribunal en otras ocasiones que cuando un caso de este tipo es objeto de litigio, un poco más y es necesario ver si se adapta a las normas y principios antes establecidos» (en Sag, 20I I: 24).

I 5. I7 U.S.C. I07 (3), The Copyright Law of the United States and Related Laws Contained in Title I7 of the United States Code. Circular 92, octubre 2009. Disponible en <http://www.copyright.gov/title I $7 />$. 
Prince of Abyssinnia: A tale, que luego Johnson reproduciría en su revista Grand Magazine of Magazines. El demandante reclamó que la copia de la publicación bordeaba los dos tercios de la obra original, afectando el mercado de ésta, generando una suerte de sustitución.

Basándose en las costumbres del período, la defensa argumentó que era usual publicar extractos de nuevos libros en revistas sin autorización de sus autores, y que incluso muchas veces eran los mismos autores los que solicitaban ser publicados en extractos, por el beneficio que éstos reportaban en las ventas de sus obras. Para el demandante, los extractos no sólo eran abusivos en su extensión, sino que también desnaturalizaban los contenidos del texto original, generando una mala imagen sobre él. A la hora de la resolución, la publicación de la revista sólo alcanzaba a reproducir una décima parte del texto original, cantidad que en opinión de la corte era insuficiente para constituir una infracción al copyright. ${ }^{16}$

En Roworth v. Wilkes, de I 807, el resumen de la enciclopedia The Art of defense on foot with the broadsword, fue denunciado por copiar 75 páginas de las i 8 de uno de los tomos de la enciclopedia. El análisis de Lord Ellenborough se redujo a determinar si la publicación del demandado sustituía la obra original.

Según Ellenborough, el factor determinante para este examen era «que este nuevo trabajo comunique el mismo conocimiento que el original» (Sag, 20 I I: 26). Finalmente, se resolvió que el resumen infringía el derecho del demandante, argumentándose que debían establecerse ciertos límites para este tipo de transcripciones, antes de permitir que se acabara con las enciclopedias modernas bajo la excusa de que por su naturaleza compilatoria podían ser resumidas con libertad.

Para Richard Godson, desde este criterio era posible presumir infracción frente a cantidades significativas de copia y que, ante casos de cantidades inferiores, la intención del acusado debía ser examinada más exhaustivamente. Para el autor, la intención de robar se relacionaba con el propósito de interferir en el mercado del autor original (Sag, 20 I I: 29).

Como muestran estos casos, lo que se repite en la gran mayoría de los del período, el criterio «cantidad copiada» era uno de los puntos de

I6. Aparentemente, entre la fecha de la presentación de la demanda y su resolución (mayo de I759 y junio de I76I), Johnson tuvo tiempo suficiente para editar su publicación y reducirla a la cantidad que la corte evaluaría como fair abridgment (Sag, 20I I: 26). 
partida del análisis, que luego iba incorporando necesariamente otros criterios que lo complementaban, en atención a las circunstancias de cada caso. Criterios como «efecto en el mercado de la obra original» y «efecto sustitutivo» eran los más comúnmente asociados a este factor de análisis.

De esta manera, la cantidad de copia tolerada por la ley variaba de acuerdo al propósito del autor del resumen y al efecto que la nueva obra generaba en el mercado del propietario de la obra original. En este sentido, Lord Chancellor Cottenham señalaba en el caso Bramwell v. Halcomb ( 1836 ):

Cuando se trata de una cuestión de cantidad, esto puede ser muy vago. Un escritor puede tomar toda la parte fundamental del libro de otro, que puede constituir una pequeña proporción del libro en cantidad. No sólo debe atenderse al libro en cantidad sino también en valor (citado en Sag, 20I I: 30).

\section{EFECTO EN EL MERCADO}

Sorprendentemente, en el debate de finales del siglo XVIII y principios del siglo XIX, el efecto sustitutivo que un resumen podía generar en el mercado era materia ampliamente conocida para la doctrina del período. En sus escritos de I 828, Robert Maugham comentaba: «De acuerdo a algunas autoridades, [los extractos de buena fe] no deben ser tan extensos como para perjudicar la venta del trabajo original, aun cuando se haya hecho sin intención de invadir al autor previo» (citado en Sag, 20II: 3I). Para Richard Godson, el abridgment es injusto cuando «inhibe al autor de su justa retribución de mercado, al dar su trabajo al público en un formato más económico» (Godson, I823: 217; citado en Sag, 20II: 3I).

En otras palabras, el efecto sustitutivo se produce con la entrada de una obra derivada al mismo mercado de su original. ${ }^{17}$ Para esta concep-

I7. Como indicó el magistrado Posner en el juicio Ty, Inc. v. Publications Internacional, «la diferencia entre un uso justo y la infracción puede ser usualmente reducido a la diferencia entre un uso complementario y un uso sustitutivo" (7th Cir. 2002, 292 F.3 d 5I2), citado en Sag (20II: 30). 
ción doctrinaria, la depreciación del valor de la obra está referida exclusivamente al daño en las ventas de la obra original. Sin embargo, catalogar un resumen como injusto exclusivamente en base a este criterio no fue frecuente. Como el mismo Maugham señalaba: «se sostiene que un resumen de buena fe de cualquier libro es considerado un nuevo trabajo; y aunque pueda dañar la venta del original, aun así no es condenado como piratería o violación del copyright» (en Sag, 20I I: 32).

El mismo autor, refiriéndose a lo resuelto por Hardwicke en Gyles v. Wilcox, quien establece que un abridgment de buena fe es el que «involucra la invención, aprendizaje y juicio del autor» en él, apunta a distinguir este elemento de examen como el punto de partida para determinar la justicia o buena fe de un resumen.

En el caso Roworth v. Wilkes se encuentra la aplicación de estos criterios. Como Maugham observa, la corte declara el abridgment injusto por el riesgo a que el resumen desplace la obra original, dado que la publicación del demandado, en palabras del Lord Ellenborough, era «sustancialmente una copia, que serviría como sustituto para el original», observando que la extensión del extracto era de tal importancia que transmitía el mismo conocimiento de la obra original.

Como puede apreciarse, el análisis en este caso funde ambos criterios para la determinación de la legalidad del abridgment: por una parte, el resumen en cuestión es declarado una copia sustancial antes que un trabajo donde el autor haya involucrado su propia inventiva. Al ser una copia, además en extenso, generaría un efecto sustitutivo en el mercado del original, perjudicando las ventas de éste.

Estas distinciones para los diferentes tipos de efectos en el mercado tienen visibles semejanzas con los criterios empleados en el debate contemporáneo del fair use. Un ejemplo de ello es el caso Campbell v. Acuff-Rose Music, Inc., de I994, en el cual la Corte Suprema de Estados Unidos explicó:

Cuando una parodia es letal [...] y mata la demanda del original, no produce un daño sancionado por el Acta de Copyright. Debido a que la parodia puede legítimamente asestar en estrangular el original, destruyéndolo comercial o artísticamente, el rol de las cortes es distinguir entre el criticismo mordaz que suprime la demanda y la infracción del copyright que la usurpa (citado en Sag, 20I I: 34). 
La noción moderna del uso transformativo, como un uso que incorpora un trabajo existente en un modo que le agrega algo nuevo, también es un factor que arroja una estrecha relación con la noción premoderna. Maugham lo sintetiza como «la aplicación de habilidades o labores que determina el carácter de buena fe de un resumen o compilación».

Esta equivalencia entre ambas nociones se expone con claridad en los escritos de Maugham, cuando sostiene:

Cuando la labor, juicio y conocimientos han sido aplicados en la adaptación de trabajos existentes en un nuevo método, y la composición ha sido hecha evidentemente con la intención justa y honesta de producir una obra nueva y mejorada, parece ser que la ley justificará la publicación, pese a que el resumen o compilación perjudique la venta de las obras anteriores (citado en Sag, 20II: 37 ).

Este criterio es transversal en la mayoría de los principales casos sobre copyright de la era premoderna de Inglaterra. ${ }^{18}$ Como anteriormente veíamos, en Gyles v. Wilcox Hardwicke explica que un resumen real y justo puede ser llamado con toda propiedad un nuevo libro, por la invención, aprendizajes y juicio del autor depositados en él. Asimismo, en Strahan v. Newbery, el resumen es reconocido como un acto de entendimiento: «El resumen que emplea entendimiento, no es un acto de plagio sobre la obra original, ni se contrapone a ninguna propiedad del autor en ella; es más bien una obra admisible y meritoria». ${ }^{19}$

La importancia del aporte autoral en el resumen destaca también en Burnett v. Chetwood. La defensa en este caso argumentó:

El traductor puede decirse que es autor, toda vez que es requisito

I 8. Strahan v. Newbery, I775; Wilkins v. Aikin, I8I0; Burnett v. Chetwood, I72I, son algunos de ellos. $\mathrm{Al}$ respecto, Godson argumentaba que «un resumen real y justo no debe ser un resumen en apariencia que omita algunas partes y transponga otras y que debe haber, a lo menos, invención, conocimientos y juicio depositados por el autor del resumen» (Sag, 20II: 38 ).

I9. Lord Chancellor Apsley en Strahan v. Newbery, I775, citado en Sag (20I I: 38 ). En Wilkins v. Aikin, de I8Io, se encuentra el mismo argumento: «de todas maneras éste es un uso legítimo de la publicación del demandante, en el justo ejercicio de una operación mental, que amerita el carácter de una obra original». 
cierta habilidad en el lenguaje, y no es simple arte mecánico, como en el caso de la reimpresión en el mismo idioma; el traductor invierte su propio estilo y expresiones, $\mathrm{y}$, por lo tanto, debiera ser parte del incentivo del acta y no de la prohibición. ${ }^{20}$

La sentencia de este caso adhiere a la defensa, declarando que la traducción constituía una nueva obra, que no caería dentro de la esfera prohibitiva del Estatuto de Ana. Este criterio del aporte autoral (uso transformativo), fue fundamental en el desarrollo doctrinario y jurisprudencial de la primera era del copyright, como lo fuera después para la gestación del fair use norteamericano.

La era premoderna del copyright de Inglaterra impactaría profundamente en los inicios del régimen de propiedad intelectual norteamericano, como lo demuestran las claras semejanzas entre los criterios elaborados en este período y los actuales factores del fair use de Estados Unidos.

Sin embargo, esta interesante continuidad contiene una distancia significativa en los alcances de la protección del copyright.

La noción premoderna planteaba estos criterios desde una concepción restringida del copyright, en que las obras derivadas son consideradas creaciones independientes y fuera del ámbito de propiedad exclusiva del autor.

El carácter derivativo del resumen o traducción no era trascendente para definir la legalidad de este tipo de obra. El examen de legalidad se fundaba en los criterios del fair abridgment. Por otra parte, la obra derivada rara vez era producida por el autor del original, y si algún beneficio se reconoció para éste en atención a su copyright sobre la obra derivada creada por otro, dicho beneficio era indirecto, a modo de publicidad, como lo demuestra el caso de Dodsley v. Kinnersley.

Como veremos más adelante, cien años después el desarrollo legislativo del copyright norteamericano redefinió el concepto de obra derivada, asignándole una jerarquía inferior a la obra original y entregando su titularidad exclusiva al autor, quien sería envestido como el titular de una esencia intelectual que compone su obra, la que puede cobrar infinitas formas de obras derivadas.

En plena discusión de sus fundamentos y alcances, el copyright nor-

20. Burnett v. Chetwood, I72I, en Sag (20II: 39). 
teamericano tomaría la experiencia británica como fuente directa en la construcción de su propio sistema, para rápidamente ampliar sus alcances y rediseñar sus fundamentos hacia un modelo más proteccionista que su precedente.

\section{GESTACIÓN DEL COPYRIGHT EN ESTADOS UNIDOS Y LA IMPORTANCIA DE FOLSOM V. MARSH}

Hacia finales del siglo XVIII, con las reminiscencias de la declaración de la Independencia aún presentes, la legislación del copyright se encontraba en un intenso flujo de enfoques en contraposición, lejos de tener sus basamentos bien establecidos (cf. Bracha, 2009). En este contexto, la experiencia del copyright de Inglaterra, con su nuevo estatuto y su vasto desarrollo jurisprudencial, resonaba con fuerza.

Como vimos más arriba, la transición que trajo el Estatuto de Ana tuvo su preámbulo en la erosión de los privilegios exclusivos entregados por largo tiempo a ciertos grupos de imprentas y editoriales, principalmente por las transformaciones comerciales y políticas de los primeros años del siglo XVIII (Gómez-Aróstegui, 20IO: I 252). Tras la entrada en vigencia del estatuto, jurisprudencia y doctrina se concentraron en delimitar sus alcances y establecer pautas interpretativas de su legislación.

Lo interesante de observar es cómo esta experiencia «heredada» fue adaptada a un contexto totalmente diverso. Estados Unidos tomó la oportunidad de instaurar un sistema ad hoc desde las lecturas económicas y políticas del copyright de Inglaterra allí donde aún no existían bases ni experiencia suficiente con su propio copyright.

En esta primera etapa del copyright norteamericano aparecen las primeras manifestaciones del discurso de la autoría original. El fundamento de la propiedad sobre las creaciones hasta entonces se remitía al antecedente británico de los derechos de imprenta y control editorial, pero no contaba con bases legales como las desarrolladas en el copyright de Inglaterra.

La ideología de la originalidad es una innovadora creación norteamericana en la concepción del copyright moderno. La imagen del autor como individuo que crea nuevas ideas a través del poder del intelecto, sumado a la reclamación de los derechos del autor - ya frecuentemente referido en ese entonces a un derecho natural de propiedad - aparecen 
por primera vez en el contexto de los State Copyright Statutes, legislado en la década de $1780 .{ }^{21}$ Uno de los preámbulos más entusiastas es el del Estatuto de Massachusett, que se refiere a los autores como «personas doctas e ingeniosas en las diversas artes y ciencias» y a la importancia de «la seguridad jurídica de los frutos de sus estudio y la industria para sí mismos», para luego concluir «esa seguridad es uno de los derechos naturales de todos los hombres, ya que no hay propiedad más peculiar propia de un hombre que la que se produce por el trabajo de su mente» (Bracha, 2009: I98).

Al tiempo de la promulgación de la Copyright Act de I790, se habían producido dos acontecimientos importantes:

- El copyright en los Estados Unidos se convirtió en el derecho de los autores. Se transformó de un privilegio ad hoc de editoriales en un régimen universal de los derechos concedidos a los autores.

- El discurso de los derechos de autor se apoyó firmemente en el mundo conceptual de la autoría y se saturó con su terminología. $\mathrm{El}$ autor fue identificado como un individuo privilegiado con una conexión única a la obra —identificación nunca antes vista- La autoría se entendió como el proceso mediante el cual un espíritu individual sirve como fuente principal de nuevas ideas originales. Esta acepción de la autoría estaba íntimamente ligada al argumento de la propiedad sobre el fruto del trabajo intelectual, basado en fundamentos del derecho natural y utilitaristas (Bracha, 2009: I99).

Esta ideología de la autoría llegaría a ser el discurso dominante del copyright, como justificación teórica subyacente a su institucionalidad. Sin embargo, esta concepción por largos años no tuvo sostén en la doctrina ni en la institucionalidad del copyright. Seguía siendo el tradicional privilegio económico de las editoriales, ahora atribuido a los autores, usándose una retórica oficial enmascarada en los derechos de propiedad autorales.

2I. La ley referida se encuentra en Copyright Enactments of the United States $1783^{-}$ I906, p. II-3I. Los doce estatutos que comprende la ley fundamentan la autoría en el derecho natural que asiste al creador sobre esta naturaleza única de propiedad (Bracha, 2009: I98). 
A principios del siglo XIX comenzó la instauración de reglas totalmente nuevas, en un afán de otorgar una realidad práctica a la nueva ideología autoral. La noción de la originalidad fue uno de los elementos fundamentales de su diseño. Según Bracha (2009), esta doctrina fue moldeada por una interacción dialéctica entre los intereses comerciales de la época y esta ideología autoral.

Hacia fines de la década de I 820 , la originalidad aparece como concepto doctrinal en numerosas disputas en que los demandados argumentaban su defensa en base a la falta de originalidad de la obra supuestamente infringida. A raíz de estas argumentaciones, se manifiesta una importante gama de intereses en contra de un requisito de originalidad exigente. Las motivaciones comerciales detrás de esta concepción de la originalidad parecen haber sido determinantes en su desarrollo doctrinario. Como consecuencia, los tribunales fueron desarrollando un discurso restringido de la originalidad, que poco tenía que ver con su noción romántica (Bracha, 2009: 20I). La originalidad como novedad sustancial o como umbral mínimo de creatividad y valor estético, fue dando paso a una noción cada vez más técnica.

La figura del juez Joseph Story fue trascendental en la instalación de esta noción restrictiva de la originalidad, al oponerse tenazmente a los argumentos de un requisito sustancial de novedad de la obra protegida. En el caso de Emerson v. Davies, de I845, declararía una especie de manifiesto de abierta oposición a los principios románticos de la ideología autoral:

Nadie escribe exclusivamente de sus propios pensamientos, sin ayuda y sin instrucción de los pensamientos de los demás. Los pensamientos de todos los hombres son, más o menos, una combinación de lo que otros hombres han pensado y expresado, si bien pueden ser modificados, exaltados o mejorados por su propio ingenio o reflexión. Si ningún libro pudiera ser objeto de un copyright, al no ser nuevo y original en los elementos que lo componen, no puede haber ninguna base para el copyright en los tiempos modernos, y estaríamos obligados a ir muy atrás, incluso a llegar a la antigüedad, para encontrar un trabajo con derecho a tal eminencia. ${ }^{22}$

22. 8 F. Cas. 6I 5 (Story, Circuit Justice, C.C.D. Mass. I 845) (No. 4436), citado en Bracha (2009: 202). 
Esta decisión del juez Story, junto a otras del período, es especialmente significativa, al representar la primera manifestación de la doctrina de la originalidad en la legislación del copyright norteamericano y porque la aparición de esta doctrina emerge sentando los cimientos del nuevo régimen de propiedad intelectual basada en los argumentos de la creatividad acumulativa y el mercado, ungiéndose este último como único criterio de evaluación del valor de la obra.

Al momento de establecer esta noción acumulativa de la creatividad, el copyright amplió radicalmente su ámbito de aplicación, y, al mismo tiempo, generó una abierta contradicción con el principio fundamental de la ideología autoral basada en la originalidad como creación única y novedosa, que a estas alturas era fundamento indiscutido del copyright norteamericano. Bracha observa esta contradicción como un diseño deliberado para la edificación de un copyright que entrega amplio control de mercado tras el pretexto de una figura mítica del autor (2009: 209-210).

Para Bracha (2009), otro elemento determinante para la comprensión de este proceso de modelación del copyright es la transformación de los fundamentos del Estado norteamericano durante este período. El surgimiento de este nuevo concepto de valor de mercado para la obra estaría estrechamente relacionado con la desaparición del gobierno del commonwealth y la proliferación del Estado liberal. El declive de la legitimidad de las evaluaciones ad hoc de valor público — desde la noción romántica de la originalidad - requería un mecanismo alternativo de evaluación y compensación. Este vacío lo llenaría el criterio de la valoración de mercado, el nuevo estandarte del emergente Estado subsidiario.

Un ensayo de 1825 de la Atlantic Magazine da clara cuenta del alcance de esta conexión entre el incipiente Estado liberal y la explícita concepción de mercado en la determinación del valor de una obra intelectual:

La oferta de la literatura y la ciencia será en proporción a su demanda y la demanda en proporción a su utilidad. Los elementos de información realmente valiosa, los principios del conocimiento útil, práctico y necesario, recibirán la mayor parte de los beneficios, ya que serán los más solicitados (citado en Bracha, 2009: 219).

En el mismo sentido, también en Emerson v. Davies, el juez Story, refiriéndose al valor de la obra, señaló que si la obra del autor era «mejor 
o peor no es materia de discusión en este caso", ya que "si no es buena, no será utilizada por la comunidad en general, y si es buena, será muy utilizada». En la conclusión fundamental, señaló que una obra «puede ser más o menos útil, pero la única importancia de esto es disminuir o aumentar los valores relativos de [...] obras en el mercado».23

De la mano de estas manifestaciones jurisprudenciales, doctrinarias y mediáticas, este enfoque de mercado para las bases institucionales del copyright se instaló de forma definitiva en el transcurso del siglo XIX. También tuvo una injerencia significativa en este proceso el nuevo rol atribuido a los jueces del período. La imagen del juez como promotor de políticas de beneficio social fue sustituida por la de un agente apolítico y neutral (Bracha, 2009: 22I). Esto fomentó el surgimiento de una concepción formalista del razonamiento legal que, sumado a la concepción del rol de la judicatura basado en las habilidades técnicas, amplificaron las otras dos tendencias, de la creatividad acumulativa y el valor de la obra determinado por el mercado.

De este modo, se logró rediseñar desde adentro el sistema del copyright, salvando la evidente brecha entre la doctrina y la teoría de la autoría original. Paulatinamente, fue posible acomodar las presiones sobre el concepto de originalidad sin necesidad de deshacerse de su fuente ideológica, suavizando sus disonancias respecto de la institucionalidad perseguida.

Sin embargo, en medio de este acelerado proceso de modelación del copyright moderno, subsistía la dificultad del alcance del copyright sobre las obras derivadas. Las traducciones, resúmenes, adaptaciones y otras obras seguían siendo reconocidas como creaciones independientes fuera del alcance de la titularidad del autor de la obra original.

El primer paso para su rediseño fue la definición del copyright como la propiedad del autor sobre un objeto intelectual, suplantando la vieja idea del copyright como la propiedad de un privilegio económico para la impresión o edición. La creación intelectual es definida como una esencia intelectual que puede adoptar diversas formas concretas, desarrolladas progresivamente. De esta forma, el copyright alcanza un control general sobre esta esquiva esencia intelectual, cualquiera sea su forma (Bracha,

23. 8 F. Cas. 620 (Story, Circuit Justice, C.C.D. Mass. I 845), citado en Bracha (2009: 220). 
2009: 226). Esta noción se instaura con las primeras legislaciones ya revisadas y fue profundizando rápidamente sus alcances.

El paso siguiente, y el más definitivo para la completa ampliación de los alcances del copyright, fue la aparición de la jerarquía entre obras originales y obras derivadas. Hacia fines del siglo XVIII y durante los primeros años del XIX — como ocurriera previamente también en Inglaterra- el discurso doctrinario se resistía firmemente a una ampliación de la protección sobre usos de obras originales para traducción, resumen o adaptación. Siguiendo los precedentes británicos, los usos o transformaciones de obras protegidas eran considerados trabajos independientes. ${ }^{24}$

El establecimiento de esta jerarquía significó que algunas obras fueran catalogadas superiores debido a su grado de originalidad, mientras que las otras fueron relegadas a un estatus inferior, en su calidad de derivadas. De esta forma, las obras derivadas pasaron a la titularidad exclusiva del autor. El autor sería en adelante concebido como el titular de cualquier nueva forma que su obra adopte, como también de todos los beneficios que recauden estas nuevas formas que adopte la esencia intelectual de su obra.

Con este cambio se terminó por sofocar el margen de libertad para los usos de obras protegidas. La protección del copyright cubre «todos los beneficios de la publicación del libro, que pueda en cualquier forma producir». ${ }^{25}$ La consecuencia inmediata de este argumento de las múltiples formas posibles de una misma esencia intelectual fue la apertura cada vez mayor del mercado de obras intelectuales, al incorporar los mercados de las obras derivadas en las bases de la protección del copyright.

El proceso de transformación conceptual llevado adelante por esta noción de la obra intelectual tuvo un desarrollo gradual, en el que el juez Story también sería protagonista. Sutilmente puso en cuestión el blindaje de los usos derivativos de obras protegidas, reproduciendo las argumentaciones británicas en torno al fair abridgment, catalogando dichos usos

24. Como se vio antes, uno de los casos británicos más influyentes en este sentido fue el de Gyles v. Wilcox, sentencia que introduciría formalmente el concepto del fair abridgment en el copyright británico, ampliando sustancialmente sus alcances.

25. George T. Curtis, A treatise on the law of copyright (I847), pp. 237-8, citado en Bracha (2009: 227). 
como no infractores, pero a la vez señalando que la determinación de su carácter de buena fe representaba una evaluación engorrosa.

Esta relativización de las defensas de los usos derivativos fue más manifiesta en el caso Gray v. Russell de $1839,{ }^{26}$ donde argumentó que el común entendido de la doctrina del abridgment como un uso que no constituye piratería del copyright original debía ser tomado con muchas precauciones. Esta sentencia amplió la protección del copyright más allá de la tradicional tipología de infracción por reproducción textual, al someter los lineamientos de protección de los usos derivativos a criterios de evaluación imprecisos.

El paso decisivo de esta cruzada por la ampliación del ámbito de aplicación del copyright se daría pocos años después, con la sentencia de Folsom v. Marsh, de I 84 I, donde el juez Story introdujo al copyright norteamericano el concepto del fair use. Irónicamente, la doctrina que hoy en día se defiende como una de las pocas herramientas de balance para la constante expansión del copyright, al tiempo de ser introducida constituyó la herramienta más idónea para la ampliación de sus alcances. Su introducción transformaría para siempre las bases del régimen de propiedad intelectual norteamericano. Los usos derivativos pasaron a ser presuntamente infractores, de no probarse la concurrencia de un fair use.

Con la incorporación del fair use —sumado a los desarrollos jurisprudenciales y doctrinarios antes revisados- la estructura moderna del copyright conseguiría cimentar sus bases fundamentales de forma definitiva, como un derecho exclusivo del autor sobre su obra original y todas sus posibles derivaciones, cualquiera fuera su forma, y como titular exclusivo de todas sus ganancias.

El fair use representaría desde entonces el sustituto para todos los usos de beneficio social que anteriormente estuvieron fuera del alcance del copyright. Lo curioso es que, si bien las motivaciones que dieron lugar a su introducción tuvieron por objetivo principal la expansión del ámbito de aplicación del copyright, su aspecto garantista, en pos de la subsistencia de márgenes mínimos para usos libres, cobró una fuerza que es de presumir no se tenía calculada.

26. Gray v. Russell. ıо F. Cas. I035 (Story Circuit Justice, C.C.D. Mass. I 839) (No. 5728), citada en Bracha (2009: 229). 
El caso litigado en I 84 I involucró dos versiones biográficas de la vida de George Washington. La parte demandante, la editorial Folsom, Wells and Thurston, titulares de los derechos de la colección The writings of George Washington, escrita por Jared Spark, acusó al reverendo Charles Upham de reproducir en su libro The life of Washington numerosos extractos de los escritos del emblemático presidente publicados en la obra de Spark. Casi un tercio de la obra de Upham consistía en escritos inéditos de Washington, presuntamente extraídos de la compilación de Spark. La publicación del reverendo habría tenido fines educativos, siendo distribuida en librerías escolares locales. La defensa de Upham argumentó: «una vez publicados los escritos y cartas del presidente, cualquier persona tiene el derecho de usar selectivamente esos materiales para preparar una obra nueva y original». ${ }^{27}$

Como vimos anteriormente, para el contexto legal de la época en Estados Unidos este argumento representaba un entendido aún comúnmente aceptado. Sin embargo, esta decisión marcaría un antes y un después en la historia del copyright.

La sentencia cita dieciséis fallos británicos y no registra ningún precedente norteamericano (Sag, 20I I: 9). Destaca entre las fuentes inglesas el caso Gyles v. Wilcox, sentencia que el juez Story replicaría con fidelidad. Citando textualmente la sentencia de I74 I, en Folsom v. Marsh se establece que:

un resumen justo o de buena fe de una obra original no equivale a piratería de derechos de autor. [...] Una mera selección, o diferentes arreglos de partes de una obra original, con el fin de reducirla a una menor extensión, no constituyen un resumen justo o de buena fe..$^{28}$

Por el contrario, agrega:

Tiene que haber una condensación real y sustancial de los materiales, y el trabajo intelectual y el juicio concedido al respecto; y no el mero

27. Este mismo argumento se repite en numerosos casos cien años más antiguos que éste (Straham v. Newbery, I774, Dodsley v. Kinnersley, I76I), analizados en el mismo artículo de Sag (20I I: 6).

28. Extracto de Folsom v. Marsh, citado en Sag (201 I: 6). 
uso fácil de las tijeras; o extractos de las partes esenciales, que constituyen el principal valor de la obra original (Sag, 20I I: 6).

Complementando este último argumento, la corte señala:

Una reseña que cita largamente la obra original para el propósito de una justa y razonable crítica, debe ser considerada justa. Por el contrario, una reseña que cita las partes más importantes de la obra sin el propósito de crítica sino el de reemplazar el uso de la obra original, sustituyéndola con el reportaje, debe ser condenada como piratería de competencia legal. ${ }^{29}$

Como puede observarse, Folsom v. Marsh importa directamente al copyright norteamericano la experiencia británica, redefiniendo el concepto de infracción del copyright ${ }^{30}$ y trazando una clara distinción entre los usos de simple reproducción y, por tanto, explícitamente infractoras del copyright, y los usos de examen exhaustivo, donde se conjugarían elementos tales como la buena fe de la producción y el aporte propio del autor, factores determinantes para reconocer un uso como justo.

De esta forma, el fair use se introduce en los tribunales norteamericanos como parte integrante del copyright, como vehículo para su ampliación y, a la vez, como garantía para la subsistencia de algunos usos secundarios.

La defensa del reverendo Upham deja entrever un contexto en que la mayoría de los usos libres sobre obras protegidas son tolerados por las autoridades; un alcance del copyright restringido, orientado exclusivamente a la infracción de reproducciones íntegras o resúmenes al pie de la letra de obras originales.

Pero el caso de Upham representa el último resabio de la antigua noción jurisprudencial del beneficio social involucrado en las adaptaciones o usos libres de obras protegidas. Para entonces, el número de casos de

29. Este argumento toma los mismos principios establecidos en Roworth v. Wilkes, I807, y Branwell v. Halcomb, I836, primeros casos donde la jurisprudencia británica plantea el factor de análisis cantidad copiada para la determinación de legalidad del abridgment.

30. Como señala Patterson, «en sus manos [en la Corte de Justicia], cualquier copia, duplicado o imitación se transformó en todo o en parte de la obra protegida. Esta redefinición de la infracción extendió el monopolio del copyright y fue la base de lo que sería el fair use» (1998, citado en Sag, 201 I: 8). 
copyright en tribunales norteamericanos era limitado ${ }^{31} \mathrm{y}$, como se vio anteriormente, la discusión doctrinaria en torno a sus fundamentos y alcances estaba en pleno desarrollo. De ahí la importancia de lo resuelto en esta sentencia; es concebida con la intención de transformarse en un referente para las bases del copyright moderno.

Es así como el fair use aparece en este contexto como la última vía de balance normativo, como instrumento que sustituye los usos de beneficio social que anteriormente estuvieron fuera del alcance del copyright. El mismo que en poco tiempo se convertiría en una valiosa herramienta para la defensa de principios democráticos como el acceso al conocimiento y el incentivo de la creatividad.

Lo interesante de observar es cómo esta mínima garantía de equilibrio normativo devino en un verdadero filtro democrático inmerso en un modelo de control autoral cada vez más restrictivo, garantía que ha resistido cambios tecnológicos, culturales, económicos y normativos por I 72 años, adaptándose cada vez, y nunca perdiendo su vigencia.

Pese a que su introducción estuvo principalmente motivada por la estrategia de expandir el copyright, es presumible que quienes estuvieron involucrados en su incorporación pudieran prever que un modelo de propiedad intelectual sin balances mínimos generaría serios conflictos sobre valores que la ciudadanía para ese entonces reconocía como propios, lo que podía eventualmente conducir al cuestionamiento de la legitimidad de todo el sistema, como ocurre en la actualidad.

¿Qué es lo que sostiene un mecanismo de las características del fair use por tanto tiempo, frente a las numerosas y constantes iniciativas que han pretendido su deslegitimación? ¿Tendrá que ver con el hecho de que, pese a todos los esfuerzos del aparato proteccionista del copyright, la creatividad de por sí no requiere un sistema legal que lo propicie y, más aún, rebusca su expresión libre por todos los medios disponibles, por estrechos o limitados que éstos sean?

El fair use se sostiene en el tiempo por la incesante ansia de crear y difundir libremente lo creado, en un escenario en que las nuevas tecnologías propician esta dirección, hacia un nuevo paradigma de conocimiento abierto y compartido que pone en jaque todo el sistema de propiedad intelectual. La creatividad define la propia naturaleza humana

3I. Se registran once decisiones sobre copyright previas a este caso (Sag, 20II: 9). 
y es inherente a ella. Podemos tener certeza de que nunca desaparecerá, pese a que su flujo sea cada vez más controlado.

\section{LA NORMATIVA DEL FAIR USE EN LA ACTUALIDAD}

La actual norma de fair use de la legislación norteamericana representa la concreción de toda la herencia jurisprudencial y doctrinaria desarrollada desde la era premoderna del copyright británico y sus posteriores desarrollos en la gestación del copyright de Estados Unidos. Es fundamentalmente el repertorio jurisprudencial británico la fuente directa de la construcción de los cuatro factores del fair use de la Copyright Act de I976, y, como veremos, aún es posible identificar su total vigencia en sus actuales aplicaciones jurisprudenciales.

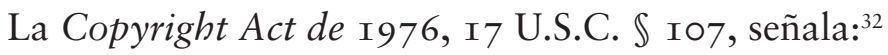

No obstante lo dispuesto en las secciones I7 U.S.C. $\$$ I06 y I7 U.S.C. $\$$ I06A, el uso justo de un trabajo protegido, incluyendo en dicho uso la reproducción en copias o fonogramas o por cualquier otro medio especificado por esa sección, para propósitos como los de crítica, comentario, reportajes, escolares (incluyendo múltiples copias para el uso en clases), universitarios o investigación, no constituye infracción al derecho de autor. Para la determinación de si el uso de una obra en cada caso particular es un uso justo, los factores a ser considerados son: I) el propósito y carácter del uso, incluyendo si se trata de un uso de naturaleza comercial o para fines educacionales sin fines de lucro; 2) la naturaleza de la obra protegida; 2) la cantidad e importancia de la parte usada en relación a la obra protegida como un todo; y 4) el efecto del uso sobre el mercado potencial o valor de la obra protegida.

Ésta no es una norma taxativa. Al contrario, se trata de una normativa de pauta dinámica que atribuye a los tribunales de justicia la tarea de determinar caso a caso, con el mérito de los antecedentes, si se trata de un uso legítimo o infractor del copyright. En este examen, pueden influir diversos factores adicionales. ${ }^{33}$

32. The Copyright Law of the United States and Related Laws Contained in Title I 7 of the United States Code. Circular 92, 2009. Disponible en <http://www.copyright.gov/ titler $7 />$.

33. Como, por ejemplo, el comportamiento de las partes en juicio, el derecho a la pri- 


\section{LOS CUATRO FACTORES DEL FAIR USE NORTEAMERICANO}

\section{PROPÓSITO Y CARÁCTER DEL USO}

Este primer factor del análisis del fair use contiene dos facetas principales: el carácter transformativo y el carácter comercial o sin fines de lucro del uso.

Carácter transformativo. «La meta del copyright, promover las ciencias y las artes, es generalmente lograda a través de la creación de obras transformativas». Así se refiere al carácter transformativo la sentencia de Campbell v. Acuff-Rose Music, de I994, decisión que generó un notorio cambio en la forma de interpretar los cuatro factores del fair use. Continúa esta sentencia: «Mientras más transformativo es el nuevo trabajo, menos peso tendrán los otros factores, tales como el carácter comercial, el que puede determinar que un uso sea declarado injusto». ${ }^{34}$

Qué es lo que constituye una obra transformativa, no ha podido ser definido con exactitud, pero como regla general si el nuevo trabajo sólo reproduce los objetos de la creación original, no es transformativo; ${ }^{35}$ si agrega algo nuevo, con un nuevo propósito o un carácter diferente, alterando el anterior con una nueva expresión, mensaje o significado, sería transformativo.

Los más frecuentes usos transformativos, enunciados en la introducción del párrafo I07, son los de crítica, comentario, reportaje de noticias y parodia (Samuelson, 2009: 2549). Esta última ha sido reconocida como un típico uso transformativo y tiene su referente más reciente en la sentencia de Campbell v. Acuff-Rose Music, Inc. El caso se motivó en

vacidad, o motivaciones ocultas para la demanda, tales como suprimir una mala crítica sobre la obra protegida. Véase Heins y Beckles (2003).

34. Campbell v. Acuff-Rose Music, Inc., 5 Io U.S. 569, 579 (I994) Supreme Court I994. Disponible en <http://scholar.google.cl/scholar_case? case= I 6686I629980405757 $73 \&$ hl $=$ en \&as_sdt $=2 \&$ as_vis $=\mathrm{I} \& o \mathrm{i}=$ scholarr\&sa $=\mathrm{X} \& \mathrm{ei}=2 \mathrm{NYUMDgK} 4 \mathrm{bc} 8 \mathrm{wT} 4 \mathrm{nIHY}$ Ag\&ved $=\circ C B c Q g A M o A D A A>$.

35. La obra de transformación es la que utiliza una obra anterior de forma tal que le otorga un nuevo significado a su predecesora, diferenciándose de ésta. En la obra derivada, en cambio, la obra original es fácilmente identificable, sin poder reconocerse diferencias importantes entre una y otra. De ahí que en este caso la ley exija la autorización del titular de la obra original para la ejecución de la obra derivada. Véase I7 U.S.C., Section IOI. 
la parodia que la agrupación de rap Two Live Crew realizó de la balada de Roy Orbison Ob Pretty Woman, tomando el estribillo central del original. El manager de la agrupación intentó conseguir una licencia del sello de Orbison, pero ésta se les negó; pese a ello, decidieron realizar y producir la parodia de todas maneras. El tema de los raperos obtuvo amplias ganancias, lo que habría generado la molestia del autor de la canción original. En primera instancia, la parodia fue declarada como fair use, dado el indiscutible carácter transformativo de la obra, decisión que sería revertida por la Corte de Apelaciones, que estableció que si bien el uso involucraba un evidente carácter transformativo a través de la parodia, la naturaleza comercial del trabajo era presumible injusto bajo el primer factor del párrafo ı07. A su vez, argumentó la Corte, al tomar el corazón de la obra original y hacerlo parte fundamental de la nueva canción, la agrupación se habría excedido en atención al tercer factor — cantidad e importancia de la parte usada-, y, por último, el daño en el mercado de la obra original quedaba establecido, en atención al cuarto factor —efecto en el mercado-, tomando en cuenta el carácter comercial del uso.

Finalmente, la Corte Suprema resolvió para este caso que una parodia comercial puede ser fair use dentro del sentido del párrafo I07, señalando: «La parodia tiene una afirmación obvia de valor transformativo, porque puede proveer beneficio social al dar nuevas luces sobre una obra previa y, en el proceso, crear una nueva». ${ }^{36}$

La Corte enfatiza que el carácter transformativo es importante no sólo por legitimar el propósito del uso del demandado, sino también la naturaleza de la obra - la parodia inevitablemente utiliza obras publicadas y populares-, la cantidad utilizada - la parodia debe utilizar fragmentos o contenidos importantes de la obra previa para lograr evocarla- y el daño al mercado de la obra original — las obras transformativas difícilmente usurpan el mercado de la obra original-.

En suma, la sentencia logra integrar en un mismo examen todos los factores del fair use a través del carácter transformativo, determinando de este modo qué factor prevalecerá. ${ }^{37}$ Antes de esta sentencia, la tendencia

36. Campbell v. Acuff-Rose Music, Inc., 5 IO. U.S. at 579, citado en Samuelson (2009: $2550)$.

37. La sentencia extrae algunos de los fundamentos de lo decidido en Folsom v. Marsh, 
en tribunales era declarar la parodia como uso injusto, toda vez que en su gran mayoría son usos de carácter comercial, basados en obras populares, que utilizan el corazón de esas obras (Samuelson, 2009: 255 I).

Otro caso que introdujo este tipo de examen fue el de Suntrust Bank v. Houghton Mifflin Co., de 200I, un buen ejemplo de uso transformativo de crítica no paródica calificado como fair use. Suntrust demandó a Alice Randall y Houghton Mifflin, su editorial, por infracción al copyright al reversionar la historia de Gone with the wind desde el punto de vista de la esclavitud, utilizando secuencias de la trama y personajes centrales de la obra original en su libro The wind done gone, que incluso incluyó diálogos textuales.

El análisis de la Corte comienza observando que la obra de Randall es una crítica específica y una réplica a la representación de la esclavitud y las relaciones entre negros y blancos en Gone with the wind. Agrega que la decisión de Randall de transmitir su crítica sobre Gone with the wind a través de una obra de ficción es justificable, dado que la autora consideró con justa razón que la ficción sería un vehículo más poderoso para entregar su mensaje que un artículo académico. Para la Corte, The wind done gone es una obra altamente transformativa, al reformular numerosas escenas y personajes, reversionando la historia desde una perspectiva radicalmente diferente para su crítica. Ante el alegato de los demandantes, que argumentaron que Randall habría tomado mucho más de lo necesario para evocar los contenidos de Gone with the wind, la Corte respondió que en Campbell v. Acuff-Rose Music, Inc. no se exigió que los parodistas tomaran una cantidad mínima y justa del material protegido por derechos de autor para evocar la obra original. Si bien la cantidad tomada de Gone with the wind fue considerable, solo podía ser juzgada excesiva si dañaba el mercado de la obra. La Corte observa que el libro de Randall, al igual que el tema paródico de Two Live Crew, difícilmente usurparía el mercado de Gone with the wind, ya que ambas obras responden a audiencias muy distintas. Los demandantes no pudieron probar daño significativo para el mercado de la obra ni de sus productos derivados autorizados.

señalando: «Miren la naturaleza y objetos de las selecciones hechas, la cantidad y valor de los materiales usados, y el grado en que ese uso puede perjudicar la venta, o reducir los beneficios, o sustituir los objetos, de la obra original». 
La Corte también se refirió al propósito de censura posiblemente encubierto en este tipo de demandas, al decir: «No se pueden usar los copyrights para proteger a Gone with the wind de los comentarios desfavorables, una política que podría extender la protección del copyright a los territorios de la censura». ${ }^{38}$

La Corte concluyó que la ley de copyright no debiera permitir que Suntrust acuse daños extraordinarios por la publicación de tipos de trabajos que ellos mismos nunca publicarían, o, lo que es peor, permitir la habilitación de un poder de censura indirecta.

Para Samuelson, los cuatro factores del fair use pueden ser agrupados en "categorías de políticas relevantes», subyacentes a ellos, complementando y profundizando el análisis de cada uno (2009: 2553). ${ }^{39}$

Los usos transformativos responderían al grupo de política relevante libertad de opinión-expresión, donde la parodia destaca como instrumento de expresión crítica y analítica. Desde esta perspectiva, como en los casos expuestos antes, es posible inferir que las reclamaciones fundamentadas en la infracción del copyright pueden esconder el objetivo de suprimir o censurar la libertad de expresión que ostenta una obra (Samuelson, 2009: 2547). ${ }^{40}$ En estos casos, el uso transformativo se transforma en el instrumento de equilibrio para la protección de los valores de libertad de expresión y opinión garantizados en la primera enmienda norteamericana, tendencia que se ha hecho cada vez más explícita.

38. Suntrust Bank v. Houghton Mifflin Co., at 268 F.3 d. I257, I Ith Circuit, U.S. Cour of Appeals, cita extraída de Samuelson (2009: 2553).

39. Samuelson argumenta que la legislación del fair use es más coherente y predecible en la medida en que se reconocen ciertos patrones comunes en los casos de fair use que pueden ser organizados en estas categorías de politicas relevantes (policy-relevant clusters). Estas políticas subyacentes al fair use incluyen la promoción de la libertad de expresión y de opinión, el continuo progreso de las autoría, el aprendizaje, el acceso a la información, la búsqueda de la verdad, la competencia, la innovación tecnológica y los intereses privados y autónomos de los usuarios. Los usos enunciados en el preámbulo del párrafo I07 estarán bajo las políticas de la promoción de la libertad de expresión y opinión, el constante progreso de la autoría y el aprendizaje.

40. La autora señala numerosos casos en que a su juicio la pretensión de censura es evidente: Nordstrom, Inc. v. Parain, I992; Nacional Rifle Association v. Handgun Control Federation, I994; Online Policy Group v. Diebold, Inc. 
Carácter comercial/sin fines de lucro. La distinción sobre si el uso es con fines comerciales o sin fines de lucro es crucial. Por largo tiempo, los usos comerciales de obras protegidas fueron presumidos injustos y de explotación. La decisión de la Corte Suprema en el caso Sony Corp. of America v. Universal City Studios, Inc., de I984, más conocido como el caso Betamax, estableció que la copia privada de programas de televisión con el reproductor y grabador Betamax, con el propósito de time shifting (visualización diferida) no constituye infracción al copyright, siendo declarado fair use, ${ }^{41}$ pero en su análisis sentó la presunción de que todo uso comercial constituiría una explotación injusta del copyright:

Pese a que todo uso comercial de obras protegidas por copyright es presumible como una explotación injusta del privilegio monopólico que pertenece al dueño del copyright, los usos no comerciales son un asunto diferente. El desafío de un uso no comercial de una obra protegida es probar que el uso en particular no es dañino, el que al ser generalizado, tendría efectos negativos en el mercado de la obra protegida (Samuelson, 2009: 254 I-2).

Sin embargo, la discusión en torno a los alcances de este factor continuó arrojando posturas opositoras a la construcción de cualquier presunción para éste. Dos años después, en Maxtone-Graham v. Burtchaell, la corte señaló:

4I. Sony Corp. of America v. Universal City Studios, Inc., I984, Supreme Court of the United States. Texto disponible en <http://www.law.cornell.edu/copyright/cases/464 US_4I7.htm>. El caso marcó un importante precedente para los usos privados o personales de nuevas tecnologías: "La cuestión es si Betamax es capaz de usos no infractores de importancia comercial. [...] Un uso potencial de la Betamax claramente cumple con este estándar, sin embargo, se entiende: time shifting en el hogar, privado, no comercial, es uso justo» (p. 443). Samuelson sobre este punto señaló: «la decisión de Sony es el legado más importante del juez Stevens en el campo del derecho de propiedad intelectual y su importancia es probable que continúe en la mediación entre las industrias de derechos de autor y los desarrolladores de tecnología de la información y los usuarios de estas nuevas tecnologías. [...] El juez Stevens fue capaz de convencer a cuatro de sus colegas a aceptar como uso justo no sólo la copia en time-shift, sino que toda copia privada no comercial debiera considerarse presuntamente justa» (2006: I32). El caso Betamax es también estudiado a fondo por Wendy Gordon (I982), entre las líneas fundamentales de su tesis de la teoría de la falla de mercado para el fair use. 
No leemos la sección I07 (I) como una exigencia a hacer una elección clara entre dos caracterizaciones opuestas entre «comercial» $\mathrm{y}$ «sin lucro». Si ese fuera el caso, el uso justo sería virtualmente anulado. El carácter comercial de un uso es una cuestión de grado y no un absoluto, y nos encontramos con que los elementos educativos de Rachel Weeping contrapesan considerablemente los aspectos comerciales del libro. Si bien el texto logró ganancias, su propósito fue, ante todo, expresar un punto de vista sobre el tema del aborto. Con 6.000 ejemplares vendidos, no fue un éxito comercial, y según todos los indicios, nunca fue concebido para eso. Por supuesto, incluso un mínimo nivel de uso comercial pesa en contra del fallo de fair use, pero que influya en la determinación final dependerá de la totalidad de los factores. ${ }^{42}$

En Salinger v. Random House, Inc., I987, el juez Leval argumentó:

Los factores a ser considerados deben incluir [...] si el uso es de naturaleza comercial o con fines educacionales, sin fines de lucro. Al decir esto, el estatuto en cierto modo dibuja irrealmente un mundo en dos esquinas: la veta comercial y la altruista. De hecho, los editores de textos educacionales tienen tanto interés por el lucro como los editores de farándula en las portadas de diarios y revistas. [...] La protección del estatuto no debiera transformarse en un cilicio o en fervor misionero. Más bien debiera orientar a la corte para hacer una valoración de la utilidad social y de un juego comercial justo. ${ }^{43}$

Tiempo después, Leval en su obra indicó: «No se debe exagerar la importancia de la distinción entre comercial y sin fines de lucro. No se sugiere en ninguna opinión o comentario responsable que por causa de esta cláusula todos los usos educacionales están permitidos y todos los usos con fines de lucro no» (I990: III6).

En Campbell v. Acuff-Rose Music, Inc. el debate jurisprudencial de los años precedentes es condensado en los siguientes términos: «El lenguaje del estatuto deja en claro que el elemento propósito comercial o educacional sin fines de lucro de una obra es sólo uno de los elementos

42. Maxtone-Graham v. Burtchaell, $2^{\circ}$ Circuit, I986. Texto disponible en <http:// www.studentweb.law.ttu.edu/cochran/Cases \% 20\&\% 20Readings/Copyright-UNT/ maxtonegraham.htm>.

43. Salinger v. Random House, Inc. 2nd. Circuit., I987. Disponible en <http://www. law.cornell.edu/copyright/cases/8 I I_F2d_9o.htm>. 
del primer factor de análisis, de propósito y carácter del uso» (en Standler, 2009: II). La sentencia se refiere a la necesidad de conservar una noción amplia para la aplicación de estos criterios, evitando la construcción de categorías de presunción:

El mero hecho de que un uso sea educativo y sin fines de lucro no lo exime de ser considerado una infracción. [...] Si el carácter comercial tomara fuerza presuntiva en contra de la constatación de la justicia del uso, la presunción aniquilaría casi todos los usos ilustrativos enunciados en el preámbulo del párrafo I07, incluyendo los reportajes, comentarios, críticas, enseñanza, investigación, dado que en este país estas actividades generalmente están motivadas por el lucro (en Standler, 2009: II).

En conclusión, el examen de este factor debe relacionarse necesariamente con los otros factores en conjunto. Así, puede darse que un uso sea justo por su calidad transformadora aun teniendo fines comerciales, como puede ser injusto un uso sin fines de lucro pero no transformativo.

\section{NATURALEZA DE LA OBRA PROTEGIDA}

Durante los últimos treinta años, los tribunales han querido delimitar el contenido de lo que representa la naturaleza de una obra a consideraciones más específicas: si la obra es creativa en oposición a la obra informativa; ${ }^{44}$ si la obra está publicada en oposición a la obra sin publicar. ${ }^{45}$

Siguiendo este criterio, la protección del sistema de derechos de autor es más intensa para expresiones creativas, y más flexible para simples acontecimientos o hechos. Consecuencia de esto es que una reutilización basada en un trabajo protegido predominantemente fáctico - como artículos de noticias - será probablemente considerado fair use. Los hechos de una noticia pueden ser reproducidos sin entrar en conflicto

44. Véase Leadsinger, Inc. v. BMG Music Publ'g, 5I2 F.3d 522, 53 I (9th Circuit. 2007). En esta sentencia, las letras de las canciones son descritas como «un trabajo de expresión creativa, en oposición a un trabajo informacional, que es precisamente el tipo de expresión que la ley de propiedad intelectual está compelida a proteger» (Sag, 20I2: I 5 ).

45. Véase Harper \& Row, Publ'rs, Inc. v. Nation Enters (I985), citado en Sag (20I2: I 5 ). 
con autorías precedentes, a menos que se reproduzca de forma textual el sentido que el autor precedente le dio a la noticia, evento en el que el uso tendría naturaleza ilegítima. ${ }^{46}$

Las obras de ficción o altamente creativas, con una protección del copyright más intensa, tornan más probable que los nuevos usos de sus expresiones sean considerados injustos. Para esta faceta del segundo factor, Sag establece la siguiente hipótesis: «Un fallo de fair use es más improbable cuando la obra del autor original es creativa» (20I2: I6).

En este sentido, en Campbell v. Acuff-Rose Music, Inc. la Corte explicó: «Algunos trabajos están más cerca del centro de la protección del copyright que otros, con la consecuencia de que el fair use es más difícil de establecer cuando las obras previas son copiadas». Sin embargo, en Campbell v. Acuff-Rose Music, Inc. la naturaleza de la obra original, esto es, una obra creativa musical, publicada y popular, es el fundamento de la efectividad de la parodia realizada por la agrupación de rap. Una parodia difícilmente podría sostenerse sin esta naturaleza de la obra original (Samuelson, 2009: 2550). Lo mismo ocurre en el caso de Suntrust Bank v. Houghton Miflin Co., en donde la obra de Randall logra su crítica social basándose en la afamada obra Gone with the wind, y es justamente gracias a la visibilidad de sus temáticas que consigue exponer su punto de vista crítico sobre las formas de discriminación y exclusión típicas de los Estados Unidos de fines del siglo XIX. En estos casos, este factor da luz verde al examen de fair use, en atención al peso del carácter transformativo de la obra.

En torno a la dicotomía obra publicada/inédita, numerosos casos entre 1985 y I 992 indican que la doctrina del fair use no era aplicable en los casos en que la obra del demandante no estaba publicada. En la sentencia sobre Harper and Row, Publishers, Inc. v. Nation Enterprises, de I985, la Corte Suprema declaró: «bajo circunstancias ordinarias, el copyright que habilita a controlar la primera aparición pública de su expresión sin difusión, pesará más que la defensa de fair use» (Sag, 2012: I6).

Esta regla fue seguida y expandida en una serie de casos del Segundo Circuito. Por ejemplo, en Salinger v. Random House, Inc. (1987) el tri-

46. Véase Harvard Law School, Signal/Noise $2 \mathrm{~K}_{5}$ Creative Revolution?, 2007, p. 6. Disponible en <http://cyber.law.harvard.edu/archived_content/events/SignalNoiseBBFINAL.pdf>. 
bunal declaró: «Los trabajos sin publicar [...] normalmente gozan de protección completa en contra de la copia de cualquier expresión protegida». En Wright v. Warner Books, Inc. (I99I), el tribunal estableció: «Los trabajos sin publicar son los hijos favoritos del segundo factor [...] nuestros precedentes dejan poco espacio para discutir este factor una vez que ha sido determinado que el trabajo protegido no está publicado» (Sag, 201 2: 16). ${ }^{47}$

Sin embargo, en 1992 la fuerza de este factor fue anulada por una enmienda al párrafo I07, la que añadió la siguiente descripción legal del uso justo: «El hecho de que una obra sea inédita no será motivo suficiente para impedir un fallo de fair use, si este fallo es hecho en consideración a todos los factores». ${ }^{48}$

En atención a estas nociones, Sag concluye que, de todas formas, es posible establecer la siguiente hipótesis: «Un fallo de fair use es menos factible cuando el trabajo del autor original es inédito» (Sag, 20 I 2: I 5 ).

\section{CANTIDAD E IMPORTANCIA DE LA PARTE USADA EN RELACIÓN A LA OBRA PROTEGIDA COMO UN TODO}

Este factor tiene sus propias peculiaridades. El entendido común es que mientras más se copia del original, más probable es que se trate de un uso injusto. Este factor no sólo atiende a la cantidad de material copiado, sino también a la calidad o relevancia de la parte sustraída de la obra original.

Una hipótesis para el entendido genérico de este factor, siguiendo a Sag, sería: «Un fallo de fair use es más probable si el acusado usa sólo una parte de la obra del autor original» (2012: I6).

Un caso emblemático en lo relativo a este aspecto cuantitativo del factor se encuentra en el polémico juicio de Grand Upright Music, Ltd. v. Warner Bros. Records Inc, de I99I ${ }^{49}$ en que se acusó al rapero Biz Mar-

47. Otro caso citado es el de New Era Publ'ns Int'l v. Henry Holt and Co (2d. Circuit. I989): "Cuando un uso es hecho de materiales de una naturaleza inédita, el segundo factor tiene que ser aplicado a favor del infractor, y nosotros no haremos eso en este caso".

48. Fair Use of Copyrighted Works Act, Pub. L. No. I02-492, I06 Stat. 3 I 45 (codified

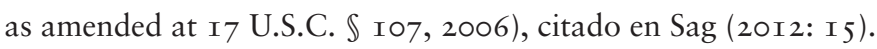

49. Detalle del juicio Grand Upright Music, Ltd. v. Warner Bros. Records Inc. disponible en <http://en.wikipedia.org/wiki/Grand_Upright_Music,_Ltd._v._Warner_Bros._Records,_Inc.>. 
kie — con firma en Warner Bros- de infringir el copyright del cantautor Gilbert O'Sullivan al samplear un fragmento de su canción Alone again (naturally). La resolución de la Corte revolucionó la música hip-hop, estableciendo que para cada futuro sampling se requiere de la autorización previa del titular de la obra protegida utilizada. Los costos de gestionar cada licencia implicaron en la práctica una importante depresión de la creatividad musical hip-hop.

A la fecha de esta sentencia seguía vigente la posibilidad de hacer uso del de minimis sampling (uso de tres acordes como máximo), lo que cambió dramáticamente tras la sentencia sobre el caso Bridgeport Music v. Dimension Films, donde se estableció como regla general la famosa cita "Get a license or do not sample». ${ }^{50} \mathrm{La}$ decisión eliminó definitivamente la doctrina del de minimis para el sampling digital, y cambió las prácticas de la industria. Pese a esto, la Corte enfatizó en esta sentencia que la decisión no excluye la procedencia de otras defensas, tales como el fair use. Sin embargo, en la práctica esta afirmación tiene poco asidero. La discusión actual apunta al enorme riesgo que corren quienes se atrevan a hacer uso de un de minimis sampling fundándose en fair use, por la falta de certeza jurídica que rodea al factor en análisis y el precedente jurisprudencial restrictivo.

No obstante, este factor involucra diversas aristas que trascienden esta noción cuantitativa. La aplicación de este factor está estrechamente vinculada al primer y cuarto factor, lo que se traduce en que la extensión de la copia admitida variará de acuerdo al propósito de la copia y al efecto de ésta en el mercado del titular del copyright de la obra original (Sag, 2012: I6).

En estos casos, puede hacerse un uso más allá de los rangos comúnmente permitidos. Por ejemplo, un uso sin fines de lucro, con propósitos educativos, podrá tomar mayor cantidad que un uso de fines comerciales con propósito educativo. Pero puede ocurrir que una utilización para parodia de fines comerciales pueda emplear la totalidad de la obra, o su parte esencial o más distintiva, sin infringir el copyright. Éste es el caso de Campbell v. Acuff-Rose Music, Inc., donde la parodia de la agrupa-

50. Bridgeport Music v. Dimension Films, 410. F.3D 792 (6th Cir. 2005), disponible en <http://en.wikipedia.org/wiki/Bridgeport_Music,_Inc._v._Dimension_Films>, cita la decisión de la Corte: «We do not see this as stifling creativity in any significant way». 
ción de rap toma el estribillo central del tema original Oh, pretty woman sin constituir una infracción al copyright. La parodia necesariamente tomará una parte fundamental de la obra original para lograr su objetivo (Samuelson, 2009: 2550). Lo mismo ocurre en el caso de la obra de Randall, donde la autora utilizó secuencias completas de la trama de la obra original, usando los mismos personajes en circunstancias casi idénticas a las de la obra original. Sin embargo, el propósito crítico de la obra ${ }^{51}$ justificó el uso excesivo del material de la obra original, siendo declarado como fair use, en atención al primer factor.

\section{EFECTO DEL USO EN EL MERCADO DE LA OBRA ORIGINAL}

Este factor tendrá poco peso en la medida de que el examen de los tres factores previos inclinen la balanza a favor del fair use.

Este factor involucra dos aspectos principales:

- si el uso en cuestión actúa directamente como un sustituto en el mismo mercado de la obra original; y,

- si existe un daño potencial en el mercado que trasciende al directo, en la existencia potencial de un mercado de licencias.

Este factor es sin duda incuestionablemente importante, pero en ningún caso se superpone a los tres factores previos. El año I985, la Corte

5I. En torno al propósito de crítica de la obra de Randall se generó un arduo debate, cuestionando si dicha crítica involucraba una parodia en el sentido de Campbell v. Acuff-Rose Music, Inc. Bajo una interpretación restringida de este término, un uso transformativo no sería parodia a menos que tuviera un carácter humorístico o pusiera la obra original en ridículo. Esta concepción de la parodia (que puede colegirse fue la empleada en Campbell v. Acuff-Rose Music, Inc.) habría puesto en peligro la defensa de Randall, dado que en su obra no había ni un germen de humor. Sin embargo, bajo una interpretación más amplia de parodia, usos críticos transformativos como The wind done gone podrían ser considerados como parodia, y el tribunal en este caso optó por esta interpretación. Finalmente, la parodia es una de las múltiples vías que los autores pueden emplear para exponer una crítica. Como Samuelson señala, «los tribunales debieran haber generalizado el marco del fair use de Campbell v. Acuff-Rose Music, Inc. y hacerlo aplicable a todas las obras que transforman desde la crítica obras previas, reformulando aspectos de la primera obra, remezclando la expresión de ella con la expresión del segundo autor, lo que arroja una nueva luz sobre el original y contribuye con nuevas perspectivas sobre su significado» (2009: $255^{\mathrm{I}-2}$ ). 
Suprema en el caso Harper and Row se refirió a este factor como «el elemento más importante del fair use». ${ }^{52}$ Este antecedente jurisprudencial influyó considerablemente la doctrina y jurisprudencia de los siguientes años, pero el debate en torno a sus alcances nunca cesó. Como se vio antes, nueve años más tarde, la decisión sobre Campbell v. Acuff-Rose Music, Inc. sepultó este precedente, estableciendo en sentido amplio que ninguno de los cuatro factores goza de primacía. Como se indica en la sentencia:

La tarea no consiste en simplificar las reglas [...] puesto que la ley al igual que la doctrina exige el análisis caso a caso. El texto emplea los términos «incluidos» y «tales como» en el preámbulo del párrafo ı०7, donde la función de los ejemplos dados es ilustrativa y no limitativa [...] y, por lo tanto, sólo proporcionan una orientación general [...]. Tampoco pueden los cuatro factores legales tratarse de forma aislada. Todos han de ser explorados y sus resultados valorados en su conjunto, a la luz del copyright..$^{53}$

Sin embargo, estudios recientes desde Campbell v. Acuff-Rose Music, Inc., han demostrado una notoria tendencia en la jurisprudencia a otorgar mayor énfasis al paradigma del uso transformativo. Como señala Sag, «la evidencia de los casos litigados [...] confirma la preponderancia del uso transformativo» (20I2: 36). En palabras de la Corte: «La creación de obras transformativas se encuentra en el centro de la garantía de la doctrina del fair use de dar un espacio para respirar dentro de los límites del copyright». .4

Pese a ello, para Sag el cuarto factor podría ser el más importante o no ser un factor en absoluto. En una investigación realizada por Beebe, el autor constató que de I4I juicios donde el factor efecto en el mercado desfavorecía al acusado, en todos salvo en uno se falló en contra del acusado en el debate final en torno al fair use (2008: 6I7, citado en Sag, 20I2: I6), lo que indica que sus alcances pueden llegar a ser de gran importancia. Sin embargo, y como veíamos anteriormente, muchas

52. Harper and Row, Publ'rs, Inc. v. Nation Enters., 47I U.S. 539, 565-66 (I985), citado en Sag (2012: I6).

53. Campbell v. Acuff-Rose Music, Inc., 5 Io U.S. 569 (el énfasis es nuestro).

54. Campbell v. Acuff-Rose Music, Inc., 5 Io U.S. 569, 579. 
veces este factor está sujeto a la tendencia que arrojen los tres factores previos. Debido a todas las diversas dimensiones involucradas en este factor, para algunos es de naturaleza camaleónica, del que difícilmente se podría establecer una presunción o línea interpretativa. En este sentido, indica Sag:

Aunque el efecto en el mercado suena a una investigación objetiva y fáctica, es de hecho una investigación muy subjetiva. En la mayoría de los casos, el criterio para determinar si la conducta del acusado infringe en conformidad al cuarto factor, es un tanto elástico, ya que para determinar la extensión de los efectos en el mercado potencial, los tribunales deben primero determinar si cierto uso se encuentra dentro del mercado potencial. [...] A la luz de esta imprecisión, la aparente simetría entre la forma en que los jueces describen el cuarto factor y los resultados de los casos de fair use, plantea la sospecha de que el efecto en el mercado no es un factor en absoluto.

\section{Continúa:}

La pregunta es: ¿hay algún contenido empírico en el cuarto factor legal o es simplemente una conclusión legal? La forma más sencilla de entender el cuarto factor es como un seguimiento de los daños por competitividad o pérdidas en ventas. Concebido como tal, la cuestión empírica sólo se sujeta a determinar ese daño o pérdida en ventas. Este seguimiento es fácil de concebir pero difícil de implementar debido a la magnitud de las pérdidas del pasado y el grado probable de pérdidas a futuro, que son elementos muy controvertidos en la mayoría de los juicios de fair use (2012: I7).

Para Sag, es posible determinar incluso intuitivamente un daño por competitividad más alto cuando demandante y acusado comparten la misma industria. Conforme a esta idea, formula la hipótesis de que «a separación de industria entre demandante y acusado hace más probable la declaración de fair use». Pero éste es uno de los múltiples criterios posibles para evaluar en qué medida este factor influirá en el examen final.

Como veíamos, la influencia de los otros factores puede ser crucial, en particular la del primer factor: mientras más transformativo sea el uso, menos posibilidades habrán de que la obra transformada genere un efecto sustitutivo en el mercado de la obra original. A contrario sensu, mientras menos transformada sea la obra, y más contenido derivativo 
tenga, más probabilidades habrá para que se produzca una sustitución en el mercado de la obra original.

La actual jurisprudencia y doctrina del fair use norteamericano da cuenta de todos los procesos históricos que modelaron el copyright, desde la era premoderna británica hasta nuestros días. Resulta llamativo el hecho de que sea el mismo modelo que respondió a las contingencias de una era tan distante a la nuestra. Sin embargo, si se observa con detención, finalmente no son circunstancias tan distintas. Transformaciones económicas, políticas y culturales ocasionadas en gran medida por los avances tecnológicos, parecen ser el principal sustento de una institucionalidad como la del fair use.

Como veíamos antes, el surgimiento del fair use estuvo principalmente motivado por el interés de ampliar el ámbito de protección del copyright. No obstante, desde sus inicios su aspecto garantista fue manifestándose con fuerza ante la constante expansión del copyright. También en este aspecto sigue siendo sumamente afín a sus primeros tiempos.

\section{CONCLUSIONES}

El estudio de los orígenes del fair use da cuenta de lo conflictiva que fue la construcción de su institucionalidad, involucrando valores y principios en constante tensión, que se resolverían de forma sigilosa como un modelo de conveniencia para la ampliación del copyright, dejando tras de sí una era de creaciones libres y difusión del conocimiento como valores activos del interés público. Sin embargo, su carácter garantista sería tomado en serio.

No deja de ser llamativo el hecho que sea la misma figura jurídica que hoy en día constituye la principal garantía para el delicado equilibrio entre los intereses de titulares de copyright y el interés público del sistema norteamericano y que, además, se haya transformado en un referente para los actuales procesos de adaptación de las legislaciones del mundo frente al fenómeno tecnológico y la consecuente expansión del copyright. ${ }^{55}$

55. En los últimos años, Israel, Corea del Sur, Bangladesh, Filipinas, Sri Lanka, Taiwán y Uganda implementaron el fair use en sus legislaciones, mientras que en Inglaterra, Canadá y Australia, entre otros, actualmente se estudia su incorporación o adaptación 
En el escenario actual, con un copyright de avanzado nivel de desarrollo en sus alcances y mecanismos de protección, repasar su historia, volver a los principios que modelaron su instauración hasta su estado actual, nos entrega perspectivas que tienden a invisibilizarse en nuestros días. El trayecto por la historia norteamericana de los principios que rigen el copyright, teniendo el antecedente británico a la vista, arroja importantes planteamientos. Comienza con la aparición de la ideología de la autoría original, reconociendo en el autor un agente merecedor de tutela jurídica especial dado el valor único de su actividad creativa, para el beneficio de la comunidad. Sin embargo, su principal requisito de la originalidad fue rápidamente disminuido hasta hacerlo desaparecer. Luego la noción del incentivo de la creatividad, propiciado por una justa retribución para los creadores. Este principio terminaría sujeto a estrictas valoraciones de mercado. La promoción del progreso de la ciencia y las artes, para el beneficio de la sociedad en su conjunto; la idea de la amplia y libre difusión del conocimiento y la información, como base del progreso y condición fundamental para la democracia.

Si observamos el resultado de esta primera era del copyright norteamericano, podríamos concluir que, efectivamente, como Bracha argumenta, estos principios inspiradores de la construcción del sistema del copyright poco tenían que ver con los verdaderos intereses en juego tras su elaboración y, más bien, cumplen desde entonces un rol de difusión y concientización para la instauración del nuevo paradigma del conocimiento como bien susceptible de apropiación privada y exclusiva.

La actual industria sobre bienes intelectuales, enraizada en las bases creadas en el período del copyright norteamericano moderno, ha dejado en evidencia que los últimos beneficiarios en la distribución de ganancias por concepto de copyright son los autores. El progreso de las ciencias y las artes ha sido cada vez más monopolizado en manos privadas y excluyentes y la difusión del conocimiento representa hoy la bestia negra del copyright, desde la aparición de nuevas tecnologías que posibilitaron el acceso por casi un siglo obstaculizado. Y mientras tanto, la producción de conocimiento continúa.

legislativa a sus principios. Un completo listado de los países con normativa de fair use y fair dealing se encuentra en Band y Gerafi (20I3). Ver más en Hargreaves (20II) y Hugenholtz y Senftleben (20II). 
Estados Unidos ha destacado históricamente por su acelerado desarrollo del conocimiento, transformándose en una de las naciones más influyentes del mundo en los últimos dos siglos. Esto fue posible en gran medida gracias al fair use. El progreso creativo, científico y tecnológico que ha logrado esta nación no hubiera sido el mismo, y sin lugar a dudas su economía no habría tenido el crecimiento económico que ha tenido en las últimas décadas, de no contar con un mecanismo flexible de acceso y uso libre del conocimiento como es el fair use. ${ }^{56}$

Este acelerado y exitoso proceso se explica también por la incorporación de medidas de incentivo para la producción nacional, como fue el bloqueo de la protección de derechos de propiedad intelectual extranjeros a lo largo del siglo XIX, ${ }^{57}$ en el entendido de que el progreso del país dependía de ello (Smiers y van Schijndel, 2008: 86-7).

Podríamos entonces concluir que elementos fundamentales para el crecimiento de los países en vías de desarrollo son: un sistema normativo equilibrado de propiedad intelectual y medidas que protejan e incentiven la producción de conocimiento. ¿No es precisamente eso lo que la nación pionera del copyright obstaculiza hoy en día?

Las recientes iniciativas que agudizan la tensión entre la sobrepro-

56. El último informe de la Computer and Communications Industry Association entidad que representa a firmas como Microsoft Inc., Google Inc., Yahoo Inc., Oracle Corporation, Sun Microsystems entre otros- destaca el importante crecimiento que han tenido en los últimos años las economías dependientes a bienes o servicios relacionados al fair use. Esto se explicaría por el fuerte ascenso de la economía digital: a través de los usos justos ha sido posible diversificar las actividades relacionadas al ámbito digital, tornándolas esenciales para muchos negocios de alta tecnología y para el comercio en la web. Según este informe, uno de cada ocho trabajadores del país del norte trabaja en alguna industria beneficiada por la protección de los usos justos, lo que equivale a I7 millones de personas trabajando en esta área, 4,7 trillones de dólares en ganancias al año 2007, 2,2 billones de dólares en valor agregado y 28I billones de dólares en exportaciones. Estas cifras representan el I 6,2 \% del PIB de Estados Unidos y siguen en aumento. Véase Computer and Communication Industry Association, "Fair use in U.S. economy. Economic contribution of industries relyin on fair use», disponible en<http.//www.wired. com/images_blogs/threatlevel/20Io/o4/fairuseeconomy.pdf>, pp. 7-I 2.

57. Comisión sobre Derechos de Propiedad Intelectual, Reino Unido. Integrando los derechos de propiedad intelectual y la política de desarrollo. $2^{\text {a }}$ edición, noviembre 2002 , p. 98, disponible en línea <http://www.iprcommission.org/papers/pdfs/Multi_Lingual_ Documents/Multi_Lingual_Main_Report/DFID_Main_Report_Spanish_RR.pdf>. 
tección de los intereses económicos de los titulares de derechos de autor y los intereses del público en general, que comienzan con los TLC impulsados por Estados Unidos, el SOPA (Stop Online Piracy Act) de 20II, ${ }^{58}$ ACTA (Anti-Counterfeiting Trade Agreemen, Acuerdo Comercial Anti-Falsificación), ${ }^{59}$ y, más recientemente, el Trans Pacific Partnership (TPP), ${ }^{60}$ proyecto que en secreto se negocia entre nueve países del Pacífico — entre ellos, Chile— persiguen instaurar de forma definitiva un derecho de acceso a la información en condiciones de control y restricción total, que pondría en jaque, entre otras garantías fundamentales, la libertad de expresión, el acceso al conocimiento, la innovación y la privacidad. ${ }^{61}$

Frente a este panorama, ¿no estaremos en condiciones de reclamar un modelo de equilibrio normativo como el norteamericano para las naciones en vías de desarrollo como la nuestra, para tener así, el tiempo

58. Véase Stop Online Piracy Act (SOPA), disponible en <http://es.wikipedia.org/wiki/ Stop_Online_Piracy_Act>.

59. Véase Acuerdo Comercial Anti-Falsificación (ACTA), disponible en <http:// es.wikipedia.org/wiki/Anti-Counterfeiting_Trade_Agreement>.

60. Un completo análisis de las principales propuestas de esta negociación y su impacto para el derecho de autor global, en Flynn y Baker (20I2). El artículo advierte que, de aprobarse esta propuesta, se alteraría gravemente el actual marco de equilibrio de intereses de titulares de derechos de autor y el interés público, al contener normas insuficientes para esos objetivos; afectaría especialmente a países en vías de desarrollo, en donde los riesgos y efectos de los costos de exclusión por mercados monopolistas de propiedad intelectual son más agudos; la orientación general de la propuesta entra en conflicto con el programa de desarrollo en actual debate en la OMPI, que contiene un enfoque más fuerte en la armonización de limitaciones y flexibilizaciones en la ley de propiedad intelectual internacional; amenaza a su vez las políticas de organismos multilaterales hacia la protección de las flexibilidades de los ADPIC, para promover el acceso a medicamentos en países en desarrollo; la propuesta realizaría estos cambios en el contexto de un nuevo y poderoso sistema de resolución de controversias que ampliaría en gran medida la situación, el lugar y las causas de acción que podrían ser utilizadas para cuestionar las políticas nacionales, incluso a través de acciones directas de empresas contra los Estados. Estas iniciativas, entre otras, muestran que se trata de una propuesta desequilibrada, que emana de un proceso de negociación viciado.

6I. Véase Electronic Frontier Foundation, Defending your rights in the digital world, disponible en <https://www.eff.org/deeplinks/20I2/o8/whats-wrong-tpp.> y Trans Pacific Partnership en <http://es.wikipedia.org/wiki/Acuerdo_Estrat\% $\mathrm{C}_{3} \%$ A9gico_ TransPac $\% \mathrm{C}_{3} \%$ ADfico_de_Asociaci $\% \mathrm{C}_{3} \% \mathrm{~B}_{3}$ n_Econ $\%_{3} \mathrm{C}_{3} \mathrm{~B}_{3}$ mica> . 
y espacio de conducir nuestro propio desarrollo? Varios países lo han entendido así, ${ }^{62}$ y sus legislaciones han sido adaptadas con el objeto de anticiparse a esta oleada proteccionista que compromete seriamente el desarrollo y la independencia y crecimiento económico, social y cultural. Nuestra legislación ya ha dado pasos tímidos en esa dirección, introduciendo un germen de fair use en la última reforma de nuestra ley de propiedad intelectual (Álvarez, 20I I).

Hoy, en el marco del Trans Pacific Partnership, es urgente reabrir este debate, con miras a la incorporación de una norma de uso justo nacional, flexible y dinámica como el fair use norteamericano y ajustada a nuestro derecho, que garantice un equilibrio regulatorio suficiente para afianzar y proteger el desarrollo científico, tecnológico, cultural y económico nacional (Ibáñez, 20I3).

\section{REFERENCIAS}

Álvarez, Daniel (20II). En busca de equilibrios regulatorios: Chile y las recientes reformas al derecho de autor. International Centre for Trade and Sustainable Development (ICTSD), Documento de Política I 2. Disponible en <http://ictsd.org/downloads/20I I/I 2/en-busca-deequilibrios-regulatorios-chile-y-las-recientes-reformas-al-derecho-deautor.pdf $>$.

BAND, Jonathan y Jonathan GERAFI (2013). The fair uselfair dealing handbook. Policybandwidth. Disponible en <http://infojustice.org/ wp-content/uploads/2013/\%3/band-and-gerafi-2013.pdf $>$.

BEEBE, Barton (2008). "An empirical study of U.S. copyright fair use opinions, I978-2005». Pennsylvania Law Review, I 56.

Bently, Lionel y Martin Kretschmer (eds.) (20I3). Primary sources on copyright (I450-I900). Disponible en <http://www.copyrighthistory. org>.

BraCHA, Oren (2009). "The ideology of autorship revisited: Authors, markets and liberal values in early american copyright». Yale Law Journal, I I 8. Disponible en <http://www.yalelawjournal.org/the-yale-law-journal/article/the-ideology-of-authorship-revisited:-authors,markets,-and-liberal-values-in-early-american-copyright/>.

62.Véase nota 55 . 
Computer and Communication Industry Association (20io). Fair use in U.S. economy. Economic contribution of industries relyin on fair use. Disponible en <http.//www.wired.com/images_blogs/threatlevel/2010/04/fairuseeconomy.pdf >.

DeAzley, Ronan (2004). On the origin of the right to copy: Charting the movement of copyright law in eighteenth-century britain (1695I775). Portland: Hart Publishing.

Defoe, Daniel (I704). «An essay on the regulation of the press». Disponible en <http://www.copyrighthistory.org/cgibin/kleioc/ooı/exec/ ausgabeCom/\%22uk_I $704 \% 22>$.

FEATHER, John (1988). A history of british publishing. Londres: Routledge.

Flynn, Sean M. y Brook BAKer (20I2). «The U.S. proposal for an intellectual property chapter in the Trans-Pacific Partnership Agreement». American University International Law Review, 28 (I). Disponible en <http://papers.ssrn.com/sol3/papers.cfm?abstract_id=2 I $85402>$.

Gomez-Aróstegui, Tomás (20I0). "The untold story of the first copyright suit under the Statute of Anne in I7Io». Berkeley Technology Law Journal, 25 (3). Disponible en <http://btlj.org/data/articles/25_3/I 247-I350\% 20Gomez-Arostegui\% 2005 I 8 I I.pdf>.

Gordon, Wendy (I982). «Fair use as market failure: A structural and economic analysis of the Betamax case and its predecessors». Columbia Law Review, 82. Disponible en <http://www.detritus.net/rhizome/legal/Gordon-Fair_Use.html>.

Hargreaves, Ian (20II). Digital opportunity. A review of intellectual property and growth. Independent report. Disponible en <http:// www.ipo.gov.uk/ipreview-finalreport.pdf>.

Heins, Marjorie y Tricia Beckles (2003). Will fair use survive? Free expresion in the age of copyright control. Brennan Center for Justice, NYU School of Law. Disponible en <http://www.fepproject.org>.

Hugenholtz, P. Bernt y Martin R. F. Senftleben (20II). Fair use in Europe. In search of flexibilities. Ámsterdam: Vrije Universiteit. Disponible en <http:/www.ivir.nl/publications/hugenholtz/Fair\%20 Use \% 20 Report $\%$ 20PUB.pdf $>$.

IвAÑEz, Carolina (2013). Fair use como modelo de flexibilización del derecho de autor. Memoria para optar al grado de Licenciado en Ciencias Jurídicas y Sociales, Facultad de Derecho, Universidad de Chile. 
Leval, Pierre N. (I990). "Toward a fair use standard». Harvard Law Review, Iо3.

Patterson, L. Ray (I998). «Folsom v. Marsh and its legacy». Journal of Intellectual Property Law, 5 (2).

Patterson, L. Ray y Stanley W. Lindberg (I99I). The nature of copyright: A law of user's right's. Athens: University of Georgia Press.

SAG, Matthew (20I I). "The Prehistory of Fair Use». Brooklyn Law Review, 76 (4). Disponible en <http://ssrn.com/abstract $=\mathrm{I} 663366>$.

-. (2012). Predicting fair use. Loyola University Chicago Law School. Public Law \& Legal Theory Research Paper 2012-05. Disponible en $<$ http://ssrn.com/abstract=I769I30>.

SAmuelson, Pamela (2006). "The Generativity of Sony v. Universal: The intellectual property legacy of Justice Stevens». Fordhamn Law Review, 74, Berkeley Center for Law and Technology. Disponible en <http://people.ischool.berkeley.edu/ pam/papers/Sony \% 2olegacy\% 20FLR.pdf>.

-. (2009). «Unbundling fair uses». Fordhamn Law Review, 77. Disponible en <http://law2.fordham.edu/publications/articles/5ooflspub 17887 . pdf $>$.

SÁnchez, María Trinidad (2004). Derechos de autor, digitalización e Internet. Madrid: Universitas.

SMiers, Joost y Marieke VAN SCHIJndel (2008). Imagine no copyright. Barcelona: Gedisa.

StAndler, Ronald B. (2009). «Fair use: No excuse for wholesale copyright infringment in the USA». Disponible en <http://www.rbs2. com/unfair.pdf>.

\section{SOBRE LA AUTORA}

Carolina Ibáñez Kollmann es abogada. Licenciada en Ciencias Jurídicas y Sociales por la Universidad de Chile. Actualmente se desempeña como abogada en Intangible Consultora. El presente artículo es una versión parcial y actualizada de su memoria para optar al grado de licenciada. Su correo electrónico es <carolinaikollmann@gmail.com>.

Este trabajo fue recibido el 30 de octubre de 2013 y aprobado el I 8 de diciembre de 2013 . 